Original Research Paper

\title{
Transformable Curved Thin Glass Greenhouse
}

\author{
Laura Galuppi \\ Department of Engineering and Architecture, \\ University of Parma, Parco Area delle Scienze 181/A, I-43124 Parma, Italy
}

Article history

Received: 10-07-2018

Revised: 05-11-2018

Accepted: 29-11-2018

Email: laura.galuppi@unipr.it

\begin{abstract}
The use of new generation thin, lightweight and damageresistant glass, originally conceived for electronic displays, is being very recently proposed for structural applications, in particular for adaptive and movable skins and façades. This paper explores this concept and presents a study on the structural use of thin glass in greenhouses for protected agriculture, based on the use of cold-twisted elements and on the exploitation of their buckling phenomena. This innovative kind of greenhouse is obtained by means of mechanisms typical of transformable architecture, as the modification of the curvature of the panels, allowing the "opening/closing" of the structure roof. The kinetics of the structure will allow to modify not only the orientation and the inclination of the different surfaces forming the greenhouse, but also size and shape of the openings. Numerical analyses and "design-by-prototyping" strategy, entailing the construction of a reduced-scale mock-up of the greenhouse, have demonstrated the feasibility of this concept.
\end{abstract}

Keywords: Thin Glass, Cold Twisting, Movable Structure, Curved Roof, Structural Design

\section{Introduction}

The external envelope of a building delimits the indoor space, controls the energy transfer between inside and outside and defines the aesthetic appeal of the building. As the demand for complex geometries, curved surfaces and improved performance increases, innovative and non-uniform envelope solutions have to be devised. Thanks to its transparency and capacity of diffusing the light and delimiting a place without the barriers of a flat wall, the use of curved structural glass is constantly growing and represents the leading feature of a modern architectural trend. Furthermore, the traditional curved glass obtained through hot-bending is being replaced by cold-bent glass. Cold-bending (Belis et al., 2007; Galuppi and Royer-Carfagni, 2015c) and coldlamination-bending techniques (Fildhuth et al., 2014; Galuppi and Royer-Carfagni, 2015a) are increasingly developing because they do not need any negative template and this leads to consistently lower costs with respect to hot bending.

In the last decade, architecture has developed new ways to respond to the flow of energy that primarily affects building performance and the comfort of the people (Linn, 2014), changing to transformable, dynamic, interactive objects, whose design is not restricted to aesthetic appearance, but goes beyond to the growing awareness of the effects of building emissions on the environment (Alotaibi, 2015). In particular, kinetic façades and movable structures proved to be an effective approach to provide natural lighting and fresh air and to increase the building energy efficiency (GhaffarianHoseini et al., 2013; Omrany et al., 2016). The architecture is now moving towards adaptive structures, i.e., kinetic structures equipped with a monitoring system to detect external/internal changes, whose information are used by a control system determining the behavior of actuators capable of changing geometry or other structural characteristics. This kind of structure is able to modify its "functions, features or behavior over time in response to transient performance requirements and boundary conditions, with the aim of improving the overall building performance" (Morales-Beltran and Teuffel, 2013; Loonen et al., 2017; Bedon et al., 2018).

In very recent years, the use in the built environment of thin glass, originally conceived for electronic screens, is beginning to take hold. Due to its high flexibility, it seems to be the optimal material for the realization of extremely deformable structural elements for façades and building skins. This opens doors for architects and designers to its pioneering use as a flexible and light 
weight cladding material. Furthermore, very recently (Silveira, 2016; Silveira et al., 2018), the use of thin glass has been proposed for the realization of adaptive façades.

Here, an innovative concept for the structural use of cold-bent thin glass is proposed. More precisely, this study explores the use of elements with hyperbolic paraboloid shape, a common geometry for cold-bent glass that may be obtained by twisting the plate through the action of opposite concentrated out-of-plane forces at the plate corners. Previous studies (Galuppi et al., 2014) have evidenced the arising of an instability phenomenon, occurring for high values of distortion, where bending is essentially unidirectional along one of the diagonals and the deformation tends to a cylindrical surface. In the present study, this buckling phenomenon is exploited to obtain shape modification with high level of distortion.

The feasibility of this pioneering concept for coldbent thin glass is here tested, in view of a stepwise approach, in a structure with relatively small scale, i.e., a transformable and movable glass greenhouse for protected agriculture. By their nature, greenhouses are structures suitable for strong modification of openings and ventilation and this make they an optimal choice to fully exploit the high-deformability potential of thin glass. However, this study could be the basis for the application of this concept in larger applications, as building façades and roofs.

The optimal management of greenhouse production is dependent on both the interior climatic factors (light intensity, ventilation, humidity, etc.) and environmental ones (dependent on season and location), as well as on physiological needs of crops. These parameters may be optimized by designing a transformable greenhouse, made by hybrid thin glass-steel panels, whose shape can be modified to vary the orientation and the inclination of the roof, as well as the openings and ventilation of the greenhouse itself. This innovative kind of structure may be obtained by means of mechanisms typical of transformable architecture, as, for example, movimentation of the substructure allowing the "opening/closing" of the structure and modification of the curvature of the panels, obtainable by tensioning or by changing the support's position. Since these modifications may strongly affect the flow of air, they have a strong impact on the ventilation of the greenhouse. Furthermore, the shape can be modified to vary the orientation and the inclination of the roof, so to change the lighting and the irradiation. The use of glass also allows for the use of specific optical/thermal coatings, suitable for different types of crops, to optimize irradiation, light intensity and heating.

This concept of movable structure could be the basis for the design of an adaptive and smart greenhouse, able to modify its shape on the basis of the required agroecosystem parameters, to obtain the most suitable and optimal conditions for the plant growth (Goel and
Gurve, 2018; Gupta and Quan, 2018). However, this paper focuses on the structural aspect of the greenhouse design, while energetic and agroecosystem issues will be the aim of further studies.

In this paper, the concept design of a greenhouse roof composed by four curved elementary cells, having the esthetic appearance of "petals", is presented. Three different strategies for the shape modification and the deformation mechanisms for the single cell are described. The different possible configurations for the roof are explored, high lighting the huge range of obtainable shapes and opening systems.

To evaluate the feasibility of the proposed concept, first geometry and materials are optimized to achieve the best structural response. Successively, the structural design of the single cell, $2 \times 2 \mathrm{~m}$ and composed by a thin glass panel contoured by a ferritic stainless steel frame with a diagonal rib, bonded by polyurethane adhesive, is performed by means of numerical analyses, by considering different design loads.

The structural design has been strictly correlated with the production of a reduced-scale model, of approximatively $0.6 \times 0.6 \mathrm{~m}$, showcasing the kinetics of the roof and its obtainable transformations. The "designby-prototyping" strategy has allowed, on one hand, to study the shape modification of the single cell and of the required movimentation for the shape modification. On the other hand, it has consistently helped the study of the geometric and kinetic properties of the whole greenhouse, the possible geometric transformations of the structure and the various obtainable shapes.

\section{Concept Design of a Movable Modular Roof}

\section{Thin Glass as a Structural Material}

Curved glass, characterizing the most recent architectural trend towards twisted and free-form shaped surfaces, may be produced either by means of hotbending and cold-bending processes. Hot-bent glass is obtained by heating sheets of glass until they reach the softening point and curving them into the desired shape against a negative form. Cold-bending, consisting in forcing in the desired position initially-flat glass elements, so to produce the curvature through elastic straining, allows for the construction of curved elements forming free-form glazed surfaces. The simplest forms that can be obtained through cold-bending are single-curvature surfaces as well as double-curved anticlastic surfaces (Galuppi and Royer-Carfagni, 2015c), whose degree of curvature can be easily modified through a slight variation of the constraining actions. Cold-bending technique is extensively used also for insulating glass units (see, among the other, (Eekhout and Niderehe, 2009; Bijster et al., 2016)). Another rtechnique, applicable to laminated glass only and usually referred to 
as cold-lamination-bending or warm-bending consists, first, in constraining the unbounded glass-interlayer package in the desired curved shape and, second, inperforming the lamination process in autoclave. Releasing the laminate, the curvature is only partially maintained through the interlayer bond (Fildhuth and Knippers, 2014; Fildhuth et al., 2014; Galuppi and Royer-Carfagni, 2014).

The use of thin glass, of thickness $s \leq 2 \mathrm{~mm}$ and of ultra thin glass (usually classified as glass under the thickness of $0.1 \mathrm{~mm}$ ) produced through the traditional float process, the down-draw process (Hou et al., 2017) and the overflow-fusion process (Lin et al., 2008; Lin and Chang, 2007), is rapidly increasing for use in flat panel displays, in particular desktop monitors and notebook computers, cell phones and video and digital cameras. Even if particular thermal treatments can be used to improve thin glass strength (see, e.g., (Boaz, 2010; Maschmeyer et al., 2018)), this material is usually chemically treated, through a process that toughens the surface of glass by replacing sodium ions with larger potassium ions (see, among the others, (Gy, 2008; Varshneya, 2010)). The ion exchange creates a thin layer of high compression on the surface which results in a layer of tension in the center. Advantages of this method include zero optical distortion, increased scratch resistance and impact strength.

In very recent years, several authors are proposing and exploiting the pioneering use of ultrathin glass for structural and architectural purposes (see, among the other, important contributions (Silveira (2016) and Ganatra (2016)). Indeed, due to its low weight, high impact and scratching resistance, excellent optical quality and its ability to be bent up to small radii, it constitutes the optimal material for the construction of deformable structural elements.

First examples of structural use of thin glass are the $11 \mathrm{~m}$ long FIFA World Cup 2014 players' bench and the lightweight retractable canopy developed by Neugebauer and collaborators (Neugebauer, 2015; Neugebauer et al., 2018), an excellent demonstrator for the potential that lies in the utilization of thin glass in movable structures. Recently, several authors have proposed the use of thin glass for the construction of kinetic and adaptive elements and façades (Topçu, 2017; Silveira et al., 2018), where this material allows to obtain the large deformations and movements required to maintain a dynamic optimum in performances with regard to energy, climate and comfort-related aspects (Bedon et al., 2018).

\section{Hyperbolic Paraboloid and Instability Phenomena}

The Hyperbolic Paraboloid shape (HP) is a quadric surface shaped like a saddle (Fig. 1a), with anticlastic double curvature. According to the classical linear Kirchhoff-Love theory (Timoshenko and WoinowskyKrieger, 1959; Galuppi and Royer-Carfagni, 2015b), this shape may be obtained starting from a flat rectangular elastic plate, simply supported in correspondence of two opposite corners and subjected to out-of-plane forces applied at the free corners. The correspondent corners move in the out-of-plane direction of the same quantity $\delta$, as indicated in Fig. 1a. In this deformed configuration, the plate edges, as well as the fibers initially parallel to them, remain straight, while the two diagonals deform into two identical parabolas, with the opposite concavity.

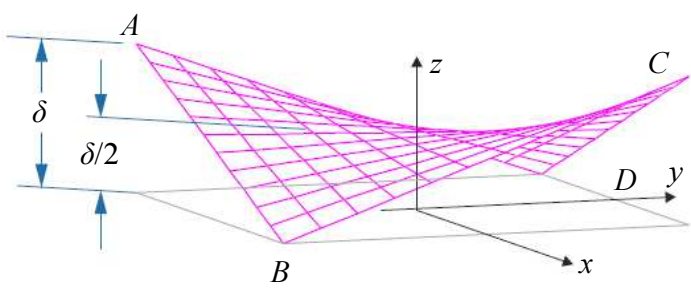

(a)

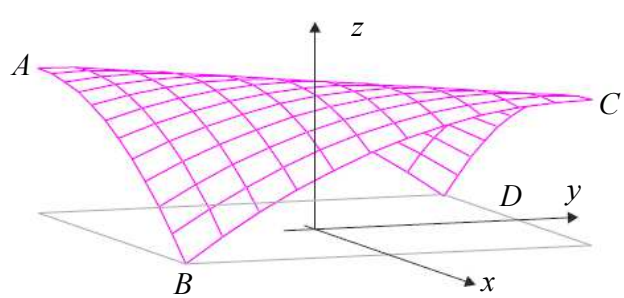

(b)

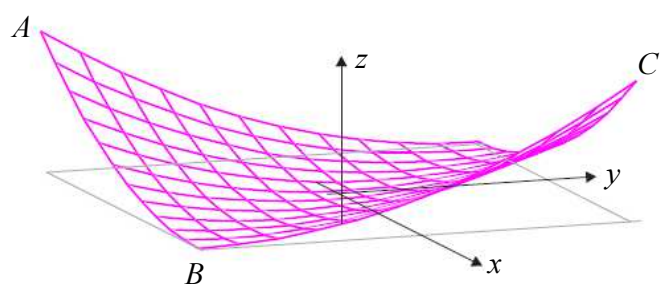

(c)

Fig. 1: (a) Hyperbolic paraboloid shape and (b) and (c) its two equivalent buckled configurations 

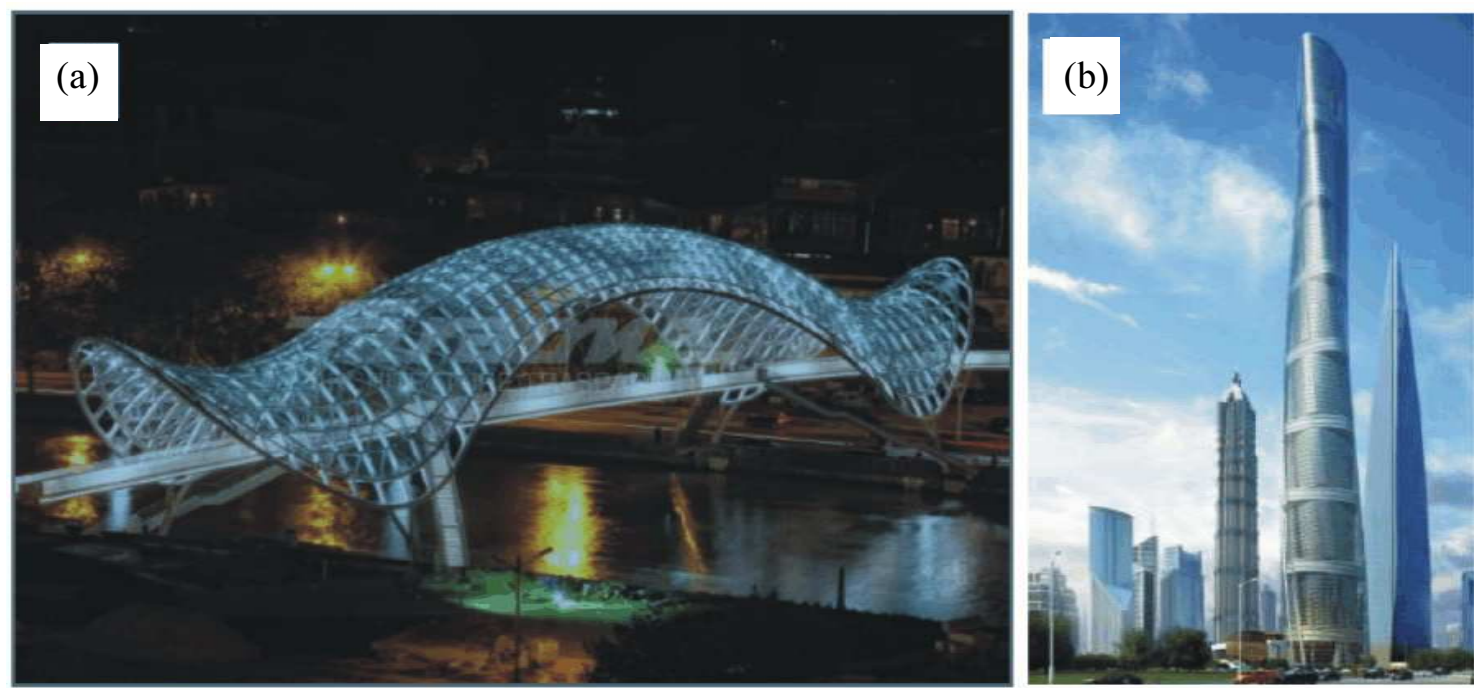

Fig. 2: Example of application of cold-bent glass panels in a HP shape: (a) Tbilisi Bridge of Peace, Tbilisi (Georgia), 2010 and (b) Shanghai Tower by Gensler, Shanghai (China), 2015

HP is one of the most used shape for the panelization of free-form surfaces (see, among the others, (MacFarlane et al., 2018; Hoffmeister et al., 2017a), in particular for glass façades and building skins. From the architectural point of view, the advantage of this shape consists in the wide range of different surfaces obtainable through the assembly of various panels obtained from identical cells by simply varying the amount of twisting.

Examples of curved glass surfaces that make use of this concept are shown in Fig. 2. The double curved surface of the Tbilisi Bridge of Peace (Fig. 2a) is panelized with cold-twisted $12+15 \mathrm{~mm}$ laminated glass panels with edge length of about $2 \mathrm{~m}$, with variable outof-plane corners' displacement $\delta$ up to approximatively $30 \mathrm{~mm}$. The external skin of the Shanghai Tower, a soft vertical spiral rotating at about $120^{\circ}$ and scaling at 55\% rate exponentially, is composed by $12+12 \mathrm{~mm}$ pointfixed laminated glass elements, up to $2.2 \times 4.5 \mathrm{~m}$, with $\delta$ of approximatively $30 \mathrm{~mm}$ (Zeljic, 2010). The obtainable curvatures are usually limited by the stress in glass.

As observed by many authors (see, among the others, (Van Herwijnen et al., 2004; de Wit, 2009; Datsiou, 2017)), at a certain level of the applied actions, or of prescribed corners' displacement, a little-known form of global instability occurs: the HP buckles into an asymmetric configuration where one of the diagonals tends to straighten, while the curvature increases in the direction of the second diagonal. In this buckled configuration, the deformed plate loses its symmetry and the edges bend. This corresponds to a change from anticlastic double curvature to approximatively single curvature shape.

Due to the plate symmetry, the unidirectional bending may equivalently occur along one diagonal or the other and there are two equivalent buckled configurations, shown in Fig. 1b (where diagonal AC is straight, while $\mathrm{BD}$ is bent) and 1c (where bending occurs along diagonal AC), respectively ${ }^{1}$.

The buckling limit $\delta^{*}$, defined as the maximum prescribed corners' displacement $\delta$ above which the asymmetry arises, strongly depends upon the glass thickness and on the aspect ratio of the panel. For square monolithic glass panels, it may be evaluated with the empirical formula proposed by Staaks (2003), i.e.:

$\delta^{*}=8.4 s$,

where $s$ denotes the plate's thickness. This relation has been confirmed by numerical parametric analyses recorded in (Galuppi et al., 2018), where also the influence of the aspect ratio for rectangular plates has been investigated.

Remarkably, all the aforementioned studies regard float glass with standard thickness. On the other hand, the cold-bending of thin and ultrathin glass into HP shape presents very particular features. Indeed, while for standard glass (with thickness of the order of centimeters) the buckling phenomena arises above a certain value of the prescribed distortion, thin glass tends to deform into a cylindrical surface also for very low values of the corners' displacement. This is in agreement with the in extensional theory for thin flat plates proposed by Mansfield (1955; 1964), according

\footnotetext{
${ }^{1}$ As in other buckling phenomena, the presence of asymmetric boundary conditions, structure imperfections and/or perturbation actions could drive the plate towards one precise configuration.
} 
to which a thin plate free to deflect along its entire periphery tends to resist to a load perpendicular to its middle plane by its flexural rigidity alone, with null strains of the middle surface of the plate. Consequently, the mode of deformation is a developable surface, with zero Gaussian curvature, allowing to maintain a low stress-level (Neugebauer et al., 2018). In the considered case, i.e., a square plate subjected to concentrated loads acting at its corners, for symmetry reasons the developable surface is a right circular cylinder whose generators are lines parallel to the straight diagonal of the plate (Fig. $1 \mathrm{~b}$ and $1 \mathrm{c}$ ).

To investigate the arising of the instability in rectangular panels, as well as the influence of geometric parameters, the case of plates of size $a \times b$, with $a, b$ varying from $1 \mathrm{~m}$ to $3 \mathrm{~m}$, made of monolithic thin glass of thickness $s \in[0.5 \div 2 \mathrm{~mm}]$, is here considered. Since, in the HP configuration, the out-ofplane displacement of the plate center is equal to $\delta / 2$ (as shown in Fig. 1a), the buckling limit $\delta^{*}$ may be conventionally defined as the maximum displacement that can be assigned to obtain a center point displacement that differs from $\delta / 2$ (Galuppi et al., 2018). Numerical analyses have been performed with Abaqus code (ABAQUS, 2010), by using a 3-D structured mesh with C3D20R elements, accounting for geometric nonlinearities. The cold-twisting process has been modeled by prescribing out-of-plane displacement to two opposite corners, leaving the other degrees of freedom ${ }^{2}$. Following the procedure used in (Galuppi et al., 2014), to enhance the rate of convergence of the FE computations, the asymmetric configuration has been "promoted" by applying an uniformly distributed out-ofplane loading to the plate, before performing the cold twisting. After removing this loading, the displacement of the central point of the plate is measured to evaluate the presence of instability phenomena.

Figure 3 shows the buckling limit $\delta^{*}$, expressed in $\mathrm{mm}$, evaluated through the described numerical parametric analyses, for monolithic rectangular glass plates of different thicknesses, as a function of the plate edge lengths $a$ and $b$. The dashed lines correspond to the case of square plate $(a=b)$. Notice that the stability of rectangular plates is higher than that of square plates, i.e., $\delta^{*}$ is higher in the former case. Furthermore, there is a mild dependence of the buckling limit on the plate size (analogue to that observed in (Galuppi et al., 2018) for glass with standard thickness), but it is negligible with respect to the dependence on the glass thickness $s$. These results confirm that relation (2.1) holds also for thin glass. Furthermore, the interpolation

\footnotetext{
${ }^{2} \mathrm{An}$ accurate investigation of the influence of other support condition on the arising of instability in coldbent glass plates is recorded in (Datsiou, 2017).
}

of the results furnish the following approximate expression for the buckling limit of rectangular plates with aspect ratio $\lambda=a / b>1$ :

$\delta^{*}=(1.5 \lambda+6.9) s$.

This equation may be regarded as the extension of Equation (2.1) for rectangular plates.

Results of FE analyses confirm that the plate buckles into a cylindrical surface (Fig. $1 \mathrm{~b}$ and 1c) for corners' displacement of the order of $1 \mathrm{~cm}$, i.e., for distortion much lower than the ones that can be appreciated with the naked eye. In the case at hand, we are interested into high distortion levels (i.e., high values of the prescribed corners' displacement), necessary to obtain not only appreciable curvatures of the greenhouse roof, but also high variability of the openings and ventilation of the greenhouse itself. Hence, it would be necessary to use the glass panel in its buckled cylindrical configuration.

Remarkably, since in the buckled configuration the plate edges are not any more straight, the global stability could be enhanced by stiffening the edges with bending-rigid braces (Galuppi et al., 2014; MacFarlane et al., 2018), i.e., by connecting the plate with a metallic frame. This would allow to obtain HP shapes with corners' displacement higher than $\delta^{*}$, i.e., to increase the buckling limit to a value dependent on the stiffness of the metallic frame. However, accurate analyses should be performed in this case, because this kind of solution could entail local instability phenomena, with consequent stress concentration in the glass panel, possibly leading to breakage.

\section{The Elementary Cell and its Possible Modifications}

According to the findings presented in the previous Section, different shape modification mechanisms could be exploited for the construction of the greenhouse roof. In the sequel, three different possibilities for the reference configuration and for the possible shape modification of a single cell composing the roof, allowing to obtain opening/closing of the greenhouse envelope, are presented.

\section{Shape Modification I - From HP to Cylindric Configuration}

A first possibility, schematically shown in Fig. 4a, is to exploit the instability phenomenon to change the shape of the thin glass panel from HP, where the plate diagonals $\mathrm{AC}$ and $\mathrm{BD}$ are two parabolas with opposite concavity, to cylindric configuration, where unidirectional bending occurs along diagonal BD. If the substructures is designed so as to fit with the straight edge of the HP panel, the geometry modification due to buckling generates an opening between the plate and the substructure itself. 

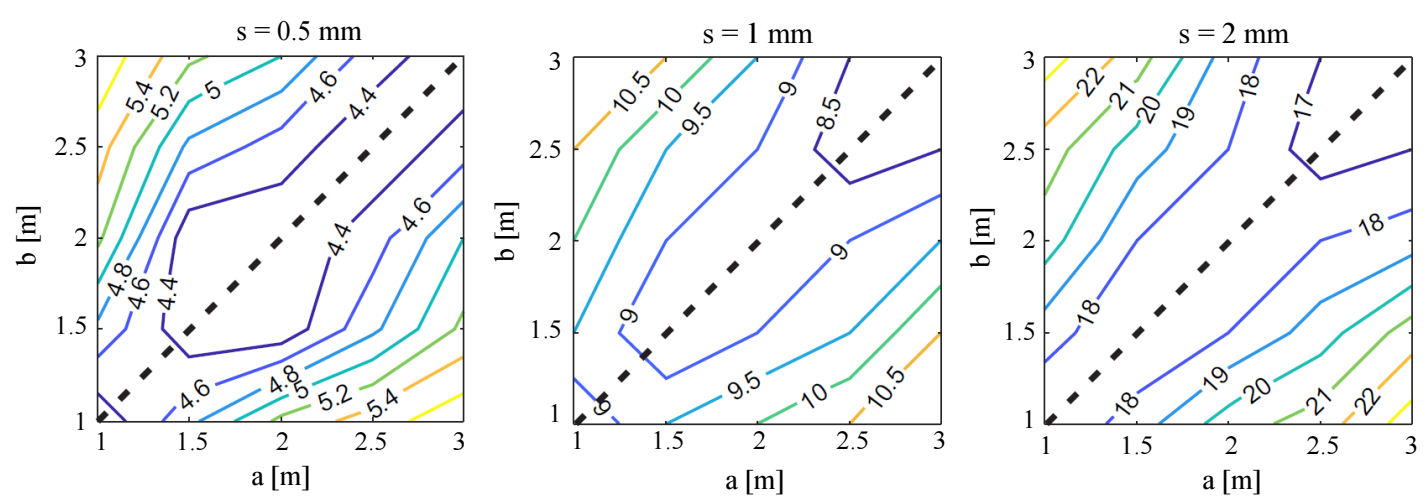

Fig. 3: Buckling limit $\delta^{*}[\mathrm{~mm}]$ as a function of the edges' length $a$ and $b$, for different plate thicknesses. Dashed diagonal lines correspond to square plates

(a)
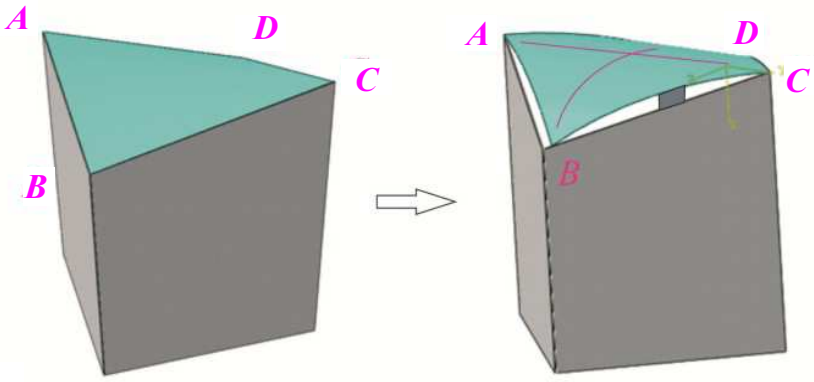

(b)

A

$D$

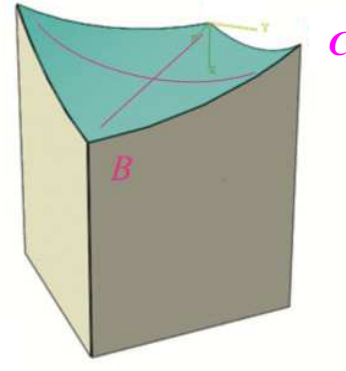

C

A

D
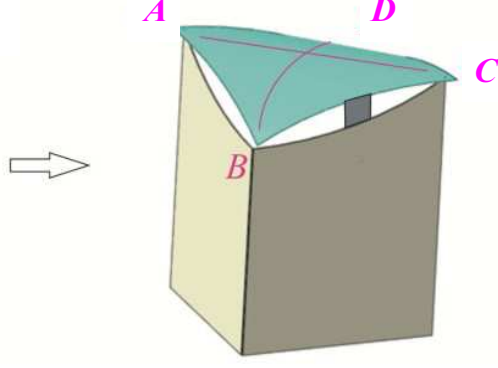

(c)
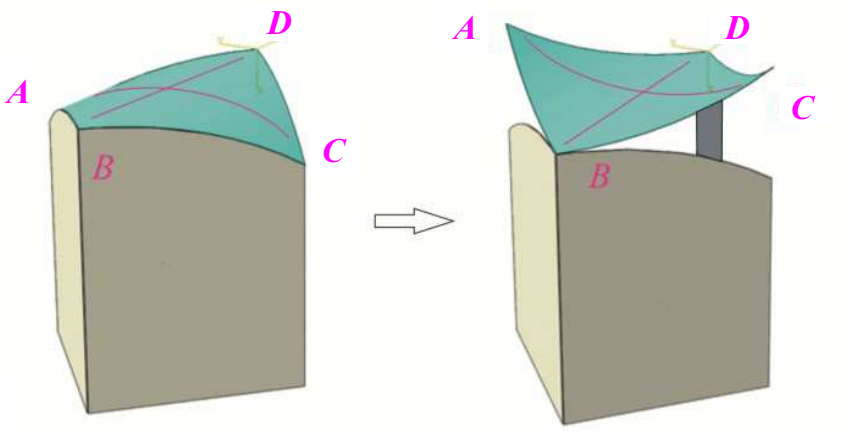

Fig. 4: Considered possible shape modifications for the cell: (a) I: from HP to cylindric configuration, (b) II: change of the bent diagonal and (c) III: change of curvature of the bent diagonal 
Remarkably, this change of configuration may be obtained in different ways, i.e., by prescribing in-plane displacements to the plate corners' (so to bring two extremes of one diagonal closer one to each other), or by changing the tensioning of the plate diagonals, as discussed in (Beatini and Royer-Carfagni, 2017). The buckling phenomenon, provoking the shape modification, may be also promoted by slightly "pushing" the plate at right angle to its middle plane by applying a load $q$. This drives the plate towards one precise configuration, i.e., the one where the concavity of the unidirectional bending is favored by $q$.

This kind of solution for the roof modification is quite difficult to obtain in real cases, because a metallic frame contouring the panel should be accurately design so to keep the HP shape for the desired amount of twisting, allowing at the same time for the buckling. Furthermore, in practical cases, the action of snow could provoke the uncontrolled buckling of the plate.

\section{Shape Modification II - Change of the Bent Diagonal}

Another possibility for the shape modification is to exploit the existence of the two equivalent buckled configurations shown in Figs. $1 \mathrm{~b}$ and $1 \mathrm{c}$. As it is schematically shown in Fig. $4 \mathrm{~b}$, it is possible to strongly modify the roof shape and consequently to open a gap between the glass panel and the substructure, by changing the plate diagonal along which bending occurs. More precisely, in the reference configuration (Fig. 4b, left-hand-side) the prescribed out-of-plane displacement is higher than the buckling limit and the bending occurs along $A C$ diagonal, while in the modified configuration (Fig. 4b, right-hand-side) diagonal $A C$ is straight and bending becomes predominant in the direction of the second diagonal $B D$. As it may be noticed by comparing Figures $4 \mathrm{a}$ and $4 \mathrm{~b}$, this second way allows to obtain consistently higher openings of the structure (the opening area is approximatively double of that obtained with shape modification I), allowing for higher changes in the ventilation of the greenhouse.

Again, the change of curvature may be obtained either by changing the tensioning of the plate diagonals or by prescribing in-plane displacements to the plate corners. Indeed, as it can be seen in Fig. $4 b$, the shape modification implies the in-plane displacement of the corners' points because, roughly speaking, the distance between the end points of the curved diagonal is lower than the diagonal length. For the "critical" value of the prescribed action/displacement, i.e., for the value that determines the change of configuration, the two configurations are somehow energetically equivalent and the structure "snaps" to the second one. However, preliminary numerical analyses have confirmed that this kind of shape modification may entail uncontrolled and abrupt change of curvature, possibly leading to stress concentration, that may provoke glass breakage.

\section{Shape Modification III - Change of Curvature of the Bent Diagonal}

A third possibility consists in changing the shape of the single cell, initially in a single-curvature configuration, by moving two corners in the vertical direction.

In this case, the reference configuration is that shown in Fig. 4c (left-hand-side), where the out-of-plane displacement of points $A$ and $C$ is higher than the buckling limit and bending occurs along the $A C$ diagonal. Starting from this configuration, the shape of the panel may be modified by keeping fixed the two corners' points $B$ and $D$, belonging to the straight diagonal, while moving the other corners in the out-ofplane direction, leaving the in-plane translational degrees of freedom. In such away, both in the reference and in the deformed configurations the bending occurs along the $A C$ diagonal, that changes its concavity. From Fig. 4, it is evident that this latter proposal allows to very impacting shape modification of the greenhouse roof.

Unlike in the other cases, here the shape change may be obtained in a gradual way, by progressively moving points $A$ and $C$ in the upward direction. In such a way, first the curvature of $A C$ diagonal decreases and, for values of the prescribed displacement lower than the buckling limit (i.e., for "almost flat" configurations, with corners' displacement of some $\mathrm{mm}$ ) the plate takes the HP shape. Then, the curvature starts to increase again, with the opposite concavity, until the desired configuration is reached. This kind of shape transformation is "smooth" and does not entail sudden changes of curvature. This solution also allows to deform the roof in several intermediate positions, correspondent to different values of the vertical displacement prescribed at points $A$ and $C$. Henceforth, this way seems to be the better solution for the construction of a greenhouse roof.

Remarkably, in this case it is of paramount importance to design a metallic frame so to provide to the element a preferential direction for the bending deformation and to force diagonal $A C$ to be the curved one. This may be done, as it will discussed in the sequel, by stiffening one diagonal by means of a metallic diagonal rib, so to have a diagonal more compliant than the other, along which unidirectional bending occurs.

Figure 5 shows the square elementary cell in the initial at configuration, plotted with continuous blue line. The same Figure shows the cold bent reference configuration (dashed red line) and the modified configuration (dashed-dotted green line), correspondent to those represented in Fig. 4c, left- and right-hand-side, respectively. 


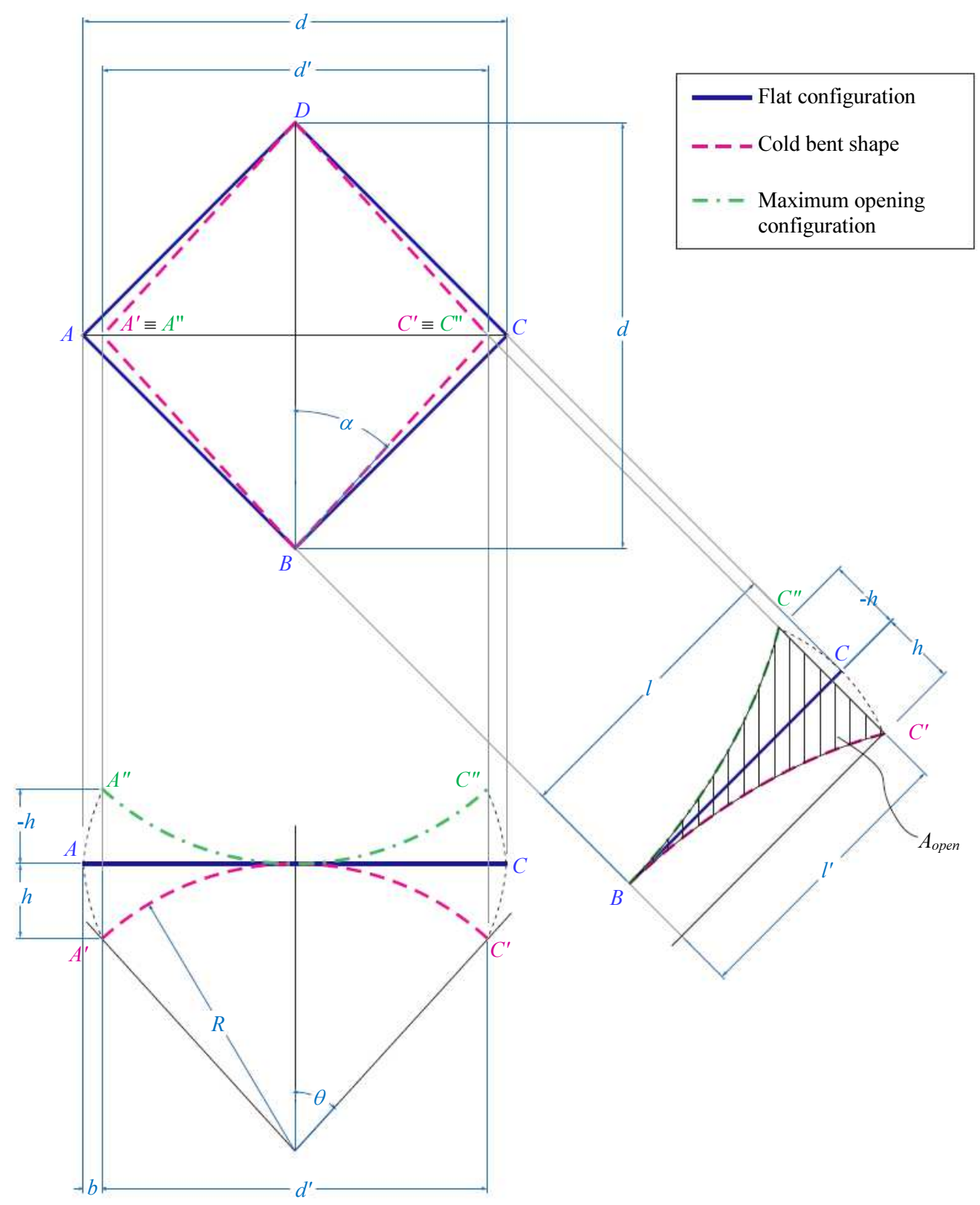

Fig. 5: Elementary cell in the flat configuration (plotted with continuous blue line), its reference cold-twisted shape (dashed red line) and the modified configuration (dashed-dotted green line)

Following the notation of Fig. 4, the bent diagonal of the cell is $A C$. Hence, points $B$ and $D$ are kept fixed, while the same out-of-plane displacement $h$ is prescribed at points $A$ and $C$. The position of these points after cold bending are denoted by $A^{\prime}$ and $C^{\prime}$, respectively. The correspondent radius of curvature $R$ and the angle $\theta$ may be obtained by solving the equation system:

$\left\{\begin{array}{l}d=2 R \theta ; \\ h=R(1-\cos \theta) .\end{array}\right.$
Since system (2.3) implies a transcendental equation for the bending angle $\theta$, with no closed-form solution, $\theta$ is plotted in Fig. 6a as a function of the ratio $h / d$. Once $\theta$ is known, graph in Fig. 6.b allows to evaluate the bending radius, for different plate diagonal length.

In the bent configuration, the projection of the cell on the horizontal plane is a rhombus, with diagonals length $d$ and $d^{d}$. The length of the projection on the horizontal plane of the curved diagonal $\left(d^{\prime}\right)$ and of the plate edge in the cold bent configuration (denoted as to $l$ ' in Fig. 5) may be evaluated as: 
$d^{\prime}=2 R \sin \theta, l^{\prime}=\frac{d^{\prime}}{2 \sin \alpha}$,

where, with reference to Fig. 5, $\alpha=\arctan \left(\frac{d^{\prime}}{d}\right)=$ $\arctan \left(\frac{\sin \theta}{\theta}\right)$. The horizontal displacement of the corner point during the cold bending processis $b=\left(d-d^{\prime}\right) / 2$. The opening area, indicated with diagonal hatched pattern in Fig. 5, may be evaluated as:

$$
A_{\text {open }}=\frac{R^{2}}{\sin \alpha}[2 \sin \theta-\sin \theta \cos \theta-\theta] \text {. }
$$

These relations will be used in the following to evaluate the openings of the greenhouse.

\section{The Greenhouse Roof}

The roof of the greenhouse may be composed by four elementary cells, whose concept has been presented in the previous Section (Shape Modification III), having the esthetic appearance of "petals", with the straight

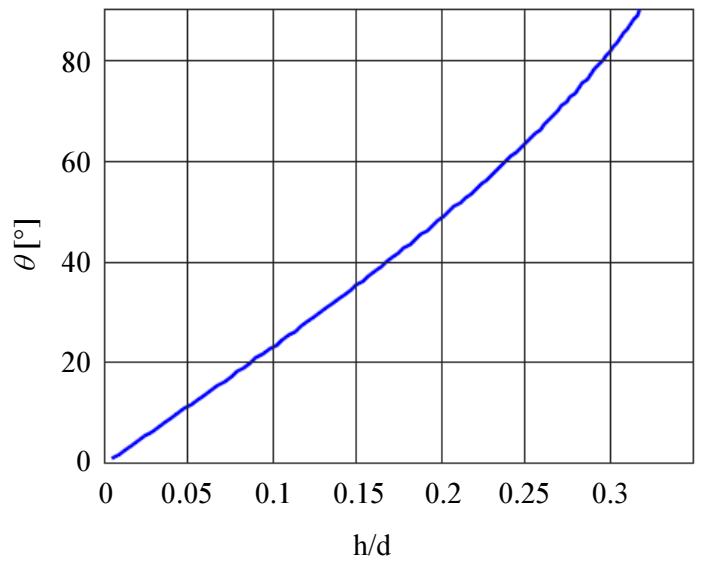

(a) diagonals of the cells converging towards the center of the greenhouse. In the reference configuration, shown in Fig. 7a, cell's vertices lying at the center and a the vertices of the greenhouse (e.g., points $B$ and $D$ ) are kept fixed, while all the corners belonging to curved diagonals (as, e.g., points $A$ and $C$ ) are moved downward of the same quantity $h$. The external walls of the greenhouse, potentially made of glass to allow for sufficient natural illumination, are designed such as there are no openings in the reference configuration.

The top view of the roof (Fig. 7b) highlights that, since in this configuration the projection of the panels on the horizontal plane are rhombi, there are empty spaces between adjacent petals and it is hence necessary to design curved ribs, supporting the inner edges of the curved cells and creating a water-and airtight barrier.

Figures 8a-e show different configurations for the roof, highlighting the huge range of obtainable shapes and of opening systems. Remarkably, this kind of structure may be used as elementary component of more complex greenhouses, through a modular assembly, as shown by Fig. 8 f.

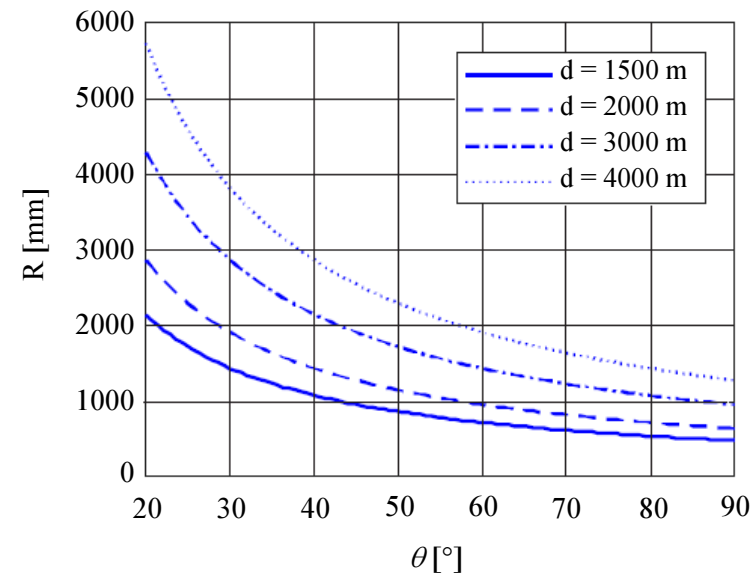

(b)

Fig. 6: (a) Relation between ratio $h / d$ and bending angle $\theta$, (b) Bending radius $\mathrm{R}$ as a function of $\theta$, for different plate diagonal length

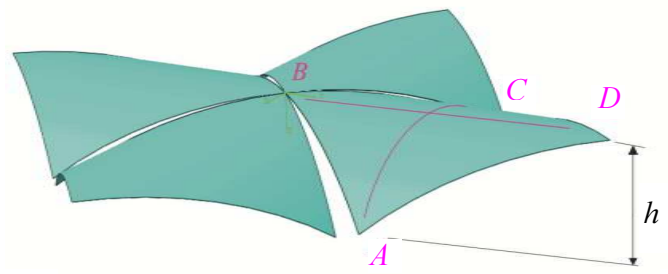

(a)

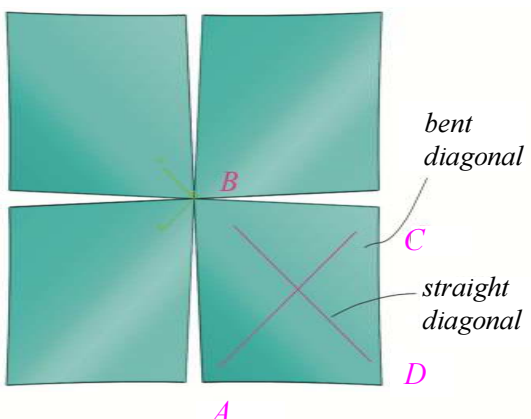

(b)

Fig. 7: Reference configuration of the greenhouse roof (a) perspective and (b) top view 


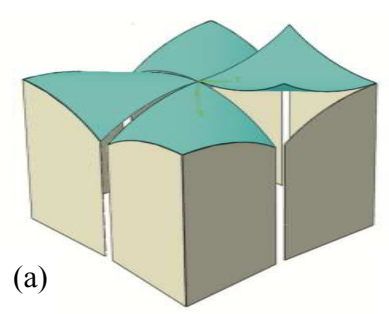

(b)

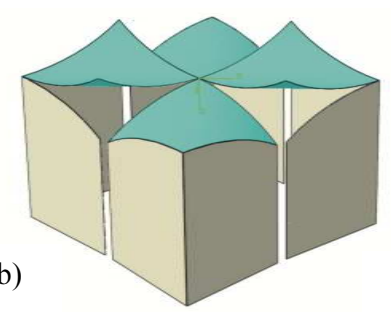

(c)

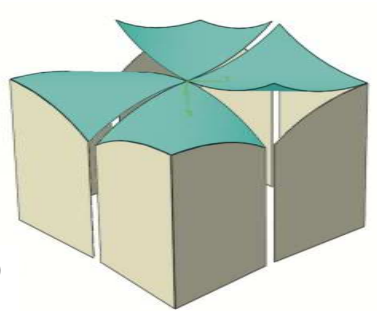

(f) (d)

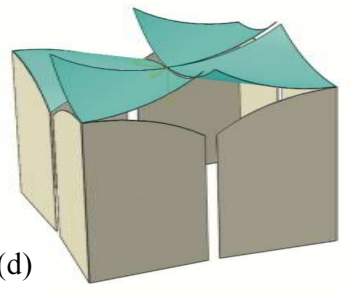

(e)

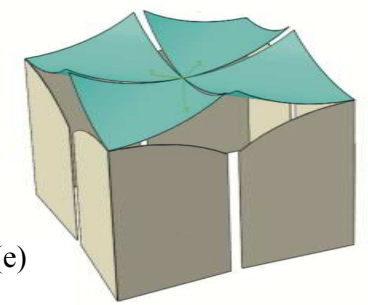

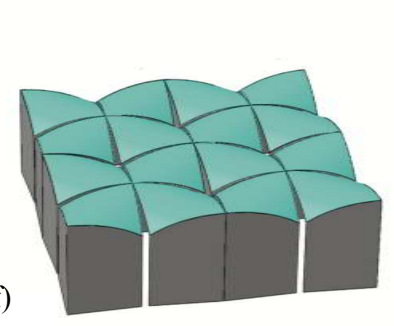

Fig. 8: (a-e) Different configurations for the greenhouse roof; (f) modular assembly

\section{Structural Analysis}

\section{Geometry and Materials Optimization}

The hybrid curved cell forming the greenhouse roof is composed by a thin glass panel contoured by a metallic frame, bonded to glass by means of structural adhesive. To confer to the hybrid cell a preferential direction to the bending deformation, necessary for the required shape modification mechanism (Fig. 4c), a diagonal metallic rib is assembled to the perimeter frame.

In a preliminary design phase, several analyses has been performed to optimize the materials and the geometry of the cell. In particular, cell size going from $1.5 \times 1.5 \mathrm{~m}$ to $2.5 \times 2.5 \mathrm{~m}$, with different thickness of the glass panel (from $0.5 \mathrm{~mm}$ monolithic to $1+1+1 \mathrm{~mm}$ laminated thin glass), have been considered. Several geometries for the metallic frame, with different materials (aluminum and different steel grades), thickness (ranging from 2 to $10 \mathrm{~mm}$ ) and width (from 50 to $100 \mathrm{~mm}$ ), have been taken into account. Different adhesive materials, both polyurethane and silicone-based, with different possible width and thickness of the adhesive strip, have been considered for the steel-glass bonding.

Results of accurate FEA performed with Abaqus code, whose results are not extensively presented here for the sake of brevity, have demonstrated that the optimal solution, in terms of structural response, is achieved by a square cell with edge length of $2 \mathrm{~m}$, composed by a thin glass panel of thickness $2 \mathrm{~mm}$, with high-performance ferritic stainless steel $^{3}$ contouring

\footnotetext{
${ }^{3}$ According to the findings of (MacFarlane et al., 2018), in steel-glass composite elements it is recommended to use ferritic stainless steel, having coefficient of thermal expansion very close to that of glass.
}

frame with one diagonal rib, with width $80 \mathrm{~mm}$ and thickness $3 \mathrm{~mm}$. The frame can be produced by assembling different steels trips. Among the considered adhesives, the most suitable for the steel-glass bonding is SikaTack ${ }^{\circledR}-M O V E$ Transportation, a monocomponent polyurethane mainly used in the replacement of windshields in busses and trucks. Since polyurethane is affected by UV radiation ageing, the possibility of cover it by a stripe of opaque printing should be considered.

As demonstrated in the sequel, this solution allows to obtain a quite high value for the out-of-plane corners' displacement, i.e., $h=500 \mathrm{~mm}$. This value is consistently higher than the buckling limit, that, according to (2.1) and graph in Fig. 3, is of about $17 \mathrm{~mm}$.

For the considered geometry and distortion, the diagonal length is $d=2820 \mathrm{~mm}$, while bending angle and radius, evaluated through Equation (2.3) (or, equivalently, by means of graphs in Fig. 6), are $\theta=42.4^{\circ}$ and $R=$ $1910 \mathrm{~mm}$. This value is higher than the minimum radius of curvature for $2 \mathrm{~mm}$ thick glass provided by (Neugebauer et al., 2018), i.e., $466 \mathrm{~mm}$. The length of the projection on the horizontal plane of the curved diagonal and of the plate edge in the cold bent configuration are $d$ $=2576 \mathrm{~mm}$ and $l^{\prime}=1913 \mathrm{~mm}$, respectively, while $\alpha=$ $42.33^{\circ}$ (reference is here made to Fig. 5).

Notice that the mechanisms for the cell movimentation should be designed so to impart the desired vertical displacement $h$, by allowing for a quite high horizontal "free" displacement of the corner point, i.e., $b=126 \mathrm{~mm}$. The opening area created on each edge of the cell by changing the curvature of one cell from the reference configuration to that with the maximum vertical corners' displacement may be evaluated by means of Equation (2.5) and turns out to be $0.6 \mathrm{~m}^{2}$. This allows for a consistent change in the ventilation, as well as in the path of the air flows. 

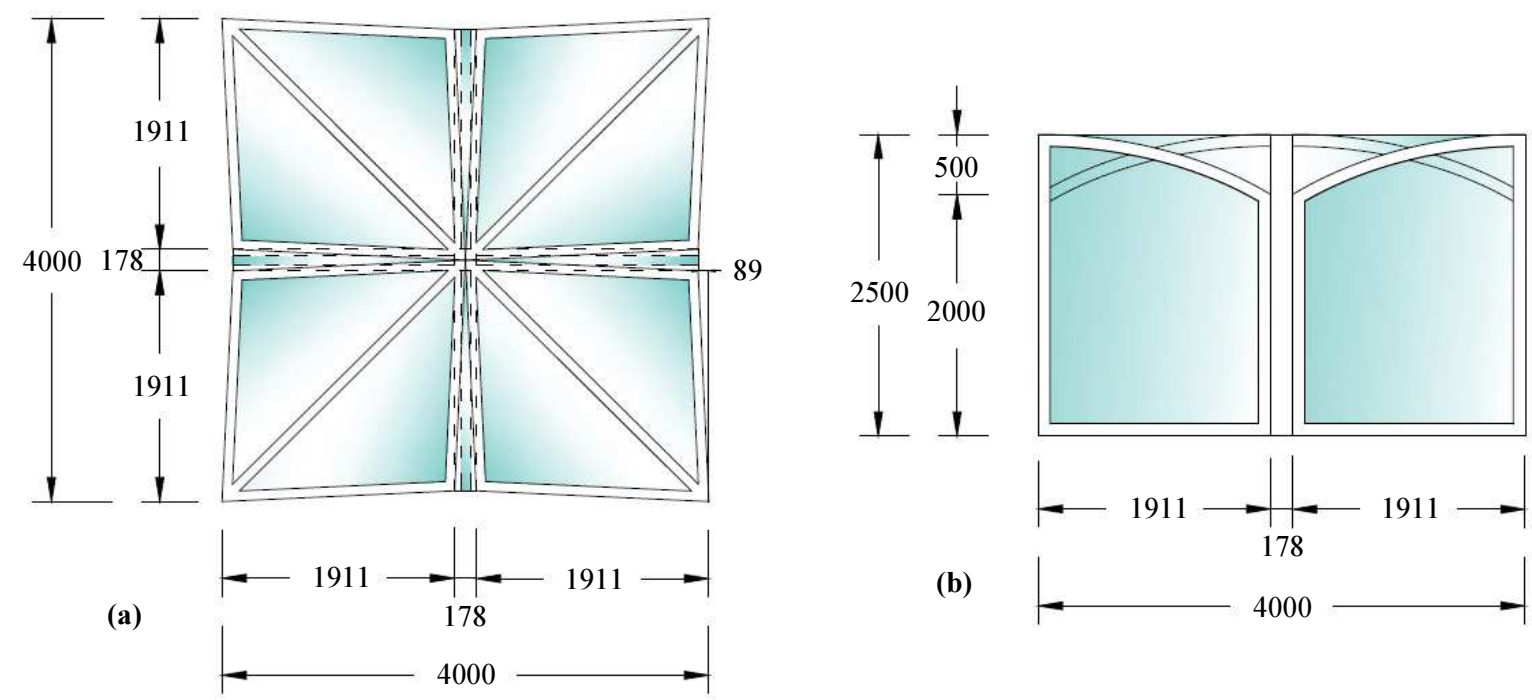

Fig. 9: Schematic of the greenhouse in the reference configuration: (a) lateral view and (b) top view

Drawings in Fig. 9 show schematics of the greenhouse's roof and substructure, in the reference "closed" configuration. The structure has approximatively square shape, with slightly concave edges, with overall size of $4 \times 4 \mathrm{~m}$ and maximum height of $2.5 \mathrm{~m}$.

\section{Numerical Investigations}

The curved hybrid cell, whose "optimal" geometry and materials have been described in the previous Section, has to be accurately designed to withstand the loads necessary to the cold bending and to the shape transformation, as well as the self weight and the snow load, in accordance with the EuroCode 1 (EN. EN19911-3: 2004). Since the roof is non-walk able, it is not necessary to consider live load coming from people working on the roof. Particular attention have been paid to the possible arising of local instability phenomena, especially during the shape modification of the roof.

Numerical analyses have been performed with Abaqus code, using a 3-Dstructured mesh with 20-node quadratic bricks with reduced integration (referred to as C3D20R in the Abaqus library (ABAQUS, 2010)). Although the choice of this kind of element causes a high computational effort, there is the advantage of getting a better quality of the computational results.

Material properties used in the FE simulation are summarized in Table 1. According to (Ganatra, 2016), the strength of thin glass have been assumed equal to $200 \mathrm{MPa}^{4}$. The adopted values for the elastic modulus and the Poisson's ratio, as well as the long-term design tensile and shear strength, of the SikaTack ${ }^{\circledR}-$ MOVE Transportation adhesive have been taken from

${ }^{4}$ Other authors (Neugebauer, 2015) suggest to use the characteristic value for chemically pre-stressed glass, i.e., $150 \mathrm{MPa}$.
(MacFarlane et al., 2018). Glass and steel components have been modeled with linear elastic material behaviour, while the Neo-Hookean hyperelastic constitutive law, traditionally used for predicting the non-linear stress-strain behavior of materials under going large deformation, has been adopted for the adhesive.

Figure 10 shows the solid model of the square steelthin glass cell, as well as the discretization used in the FE analyses. As shown in the magnified detail, the mesh has been created by dividing the thickness of the adhesive in 3 elements, to correctly assess local problems of adhesive. Tie constrains have been applied to the steel-adhesive and adhesive-glass interfaces. The FE simulations do account for the self-weight and for geometric non-linearities.

\section{Cold Twisting}

In the first step of the numerical experiments, the cold-twisting of the cell is performed, by prescribing a out-of-plane downward displacement $h=500 \mathrm{~mm}$ to two opposite corners, while leaving their in-plane translational and the rotational degrees of freedom.

The out-of-plane displacement field shown in Fig. 11a confirms that the deformed shape of the cell is cylindrical in type. Figure $11 \mathrm{~b}$ shows the maximum principal stress distribution in the glass panel after cold bending. It may be verified that the maximum value for the stress (of the order of $120 \mathrm{MPa}$ ) is lower than the characteristic thin glass strength.

Figure 12a show the distribution of Von Mises equivalent stress in the steel frame, limited to $300 \mathrm{MPa}$, i.e., the assumed value for the steel design strength, plotted on the deformed shape. The Von Mises stress exceeds this value only in very localized regions of the frame, in proximity of the junction between external frame and diagonal rib. 
Table 1: Material properties used in the FE simulation

\begin{tabular}{|c|c|c|c|c|c|}
\hline Material & $E[\mathrm{MPa}]$ & $v[-]$ & $\begin{array}{l}\text { Maximum Von } \\
\text { Mises stress [MPa] }\end{array}$ & $\begin{array}{l}\text { Maximum tensile } \\
\text { stress [MPa] }\end{array}$ & $\begin{array}{l}\text { Mximum shear } \\
\text { stress [MPa] }\end{array}$ \\
\hline Thin glass & 70000 & 0.22 & - & - & $200[20]$ \\
\hline Steel & 210000 & 0.3 & 300 & - & - \\
\hline Adhesive & 5 & 0.47 & - & $0.16[38]$ & $0.16[38]$ \\
\hline
\end{tabular}

(a)

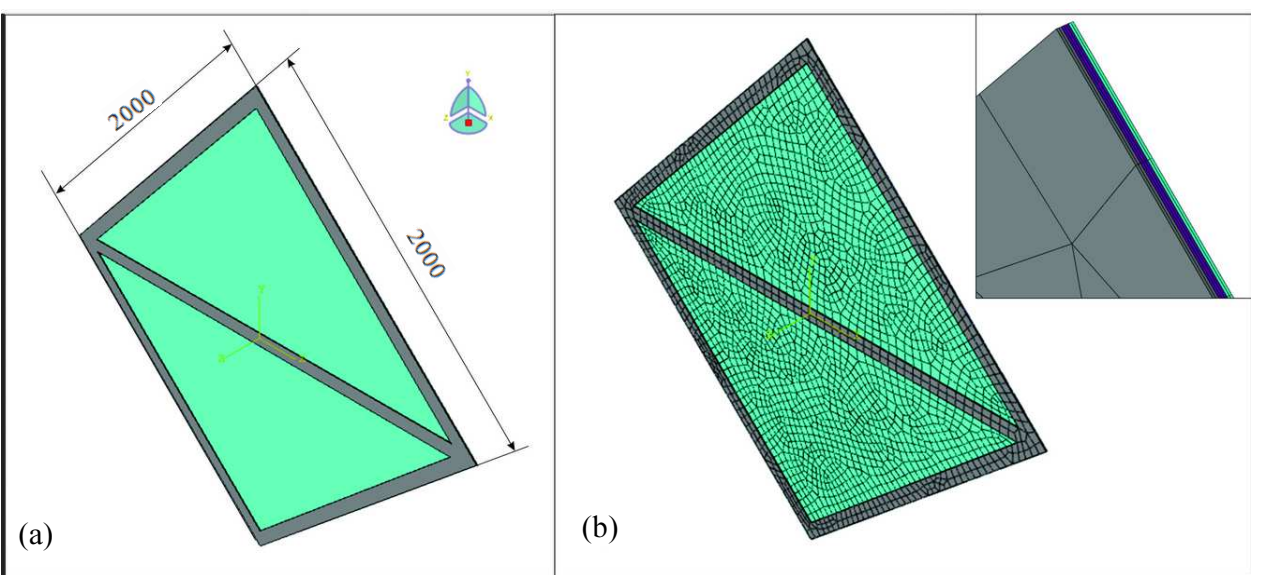

Fig. 10: Solid model of the thin glass-steel cell and particular of the discretization

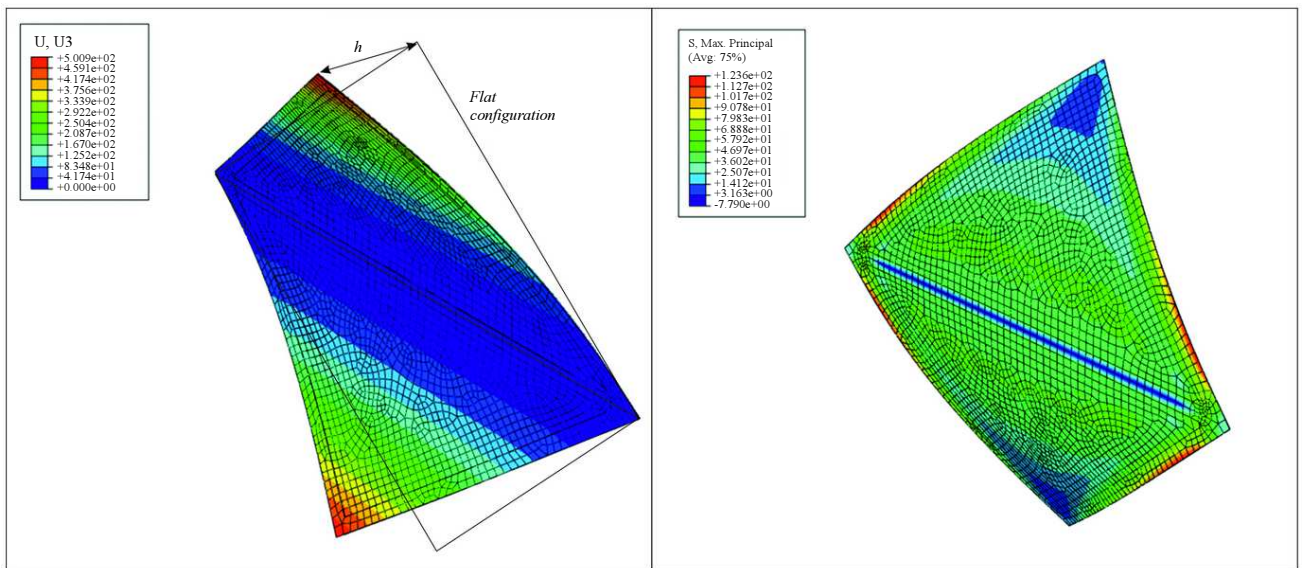

Fig. 11: Cold twisting. Results of FE analysis, in terms of (a) out-of-plane displacement and (b) maximum principal stress in the thin glass panel

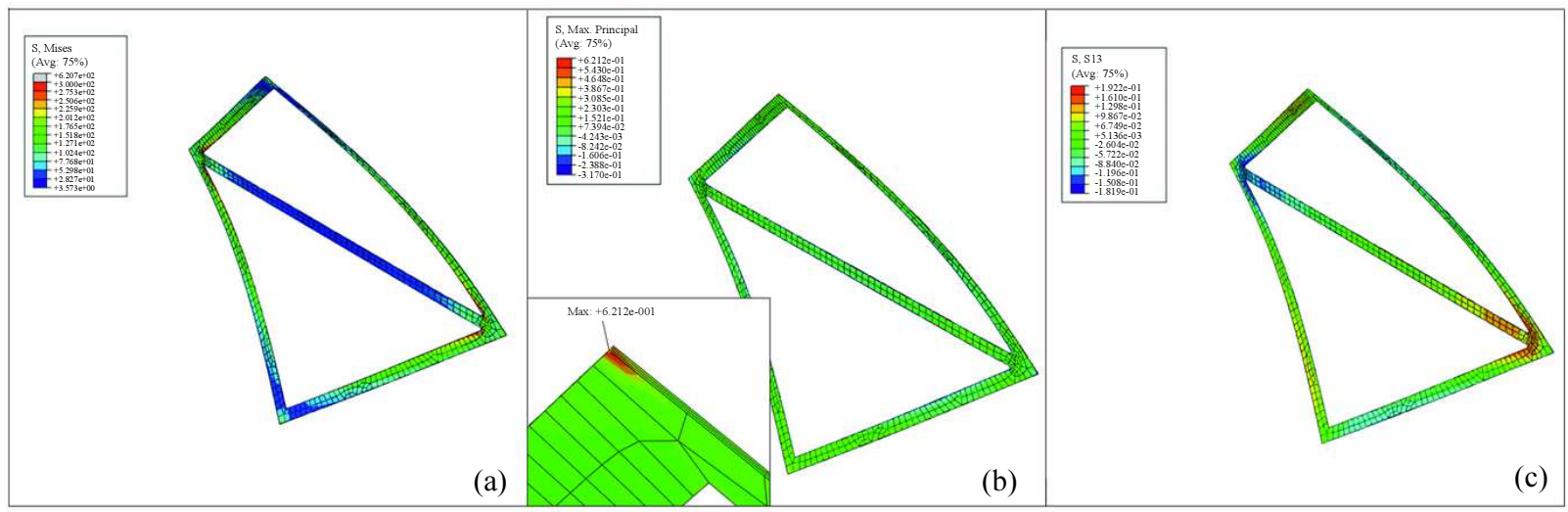

Fig. 12: Cold twisting. Results of FE analysis, in terms of (a) Von Mises stress in the steel frame, (b) maximum tensile stress and (c) shear stress in the adhesive 
Plots in Fig. 12b and 12c presents the results obtained from the numerical analysis in terms of maximum tensile and shear stress in the adhesive strips, respectively. The maximum tensile and shear stress, higher than the design values, are localized in a very small region in correspondence of the strips' corners (see magnified detail in Fig. 12b), while the mean stress on the adhesive is considerably lower than the maximum allowable stress, i.e. $0.16 \mathrm{MPa}$. The maximum out-of-plane downward displacement for which the allowable shear/tensile stress in the adhesive strip is achieved is of the order of 150 mm. However, according to (MacFarlane et al., 2018), since the viscoelasticity of the adhesive allows a certain redistribution of the stresses, this solution can be considered acceptable. Remarkably, this kind of stress concentration at the strips' corners could be reduced by using chamfered or rounded corners for the composite cell (MacFarlane et al., 2018).

\section{Snow Load}

Numerical analyses have been performed by considering the combination of self-weight and snow load, acting on the (cold-twisted) reference configuration of the cell, by considering the cell edges to be continuously supported by the underlying structure. EuroCode 1 (EN. EN1991-1-3: 2004) states that the design shall recognise that snow can be deposited on a roof in many different patterns. The snow action is here evaluated by considering Mediterranean areas and two different load cases are considered: (i) undrifted snow arrangement, with uniformly distributed load of 0.8 $\mathrm{kN} / \mathrm{m}^{2}$ and (ii) wind-drifted snow arrangement, correspondent to the load distribution shown in Fig. 13.

Results of FE analyses have provided evidence that, due to the curvature of thin glass, the panel is very stiff and the deformation due to the snow load is almost negligible if compared to the cold twisting deflection. Also the increase of stress is very limited. The second load case is the most onerous for what concerns the glass stress, which maximum value increases from 123.6 to 126.9 $\mathrm{MPa}$, while stresses in steel and adhesive are slightly higher in the first case. Again, apart from stress concentrations located in very small areas in proximity of the corners and at the frame - rib intersection, the recorded stress are lower than the material strength.

\section{Shape Modification}

The cell response during the shape modification of the greenhouse's roof have been evaluated by means of FE analyses. As discussed in Section 2.3, the shape of the panel may be modified by keeping fixed the two corners' points belonging to the straight diagonal, i.e., that correspondent to the center and a vertex of the greenhouse, while moving the other corner's points in the vertical direction, as shown in Fig. 8. Here, an out-of-plane displacement of $2 h=1 \mathrm{~m}$ with respect to the reference configuration is considered, so to obtain the final shape represented in Fig. 5. In the numerical analyses, such a modification has been obtained in a gradual way, by progressively moving the corners of the plate, to carefully evaluate the possible arising of local buckling, potentially leading to glass breakage due to stress concentrations. The results have demonstrated that no local instability phenomena arise during the deformation process.

Figures $14 \mathrm{a}$ and $14 \mathrm{~b}$ show the out-of-plane displacement of the cell and the distribution of the maximum principal stress in the thin glass panel. Also in this case, the deformed shape of the panel is cylindrical and the maximum stress in the pane is lower than the thin glass design strength. Values of maximum Von Mises stress in the steel frame and tensile and shear stress in the adhesive are comparable to those achieved in the cold bending phase and recorded in Sect. 3.2.1. Again, since the viscoelastic properties of the adhesive allows a redistribution of the stresses, this solution can be considered acceptable.

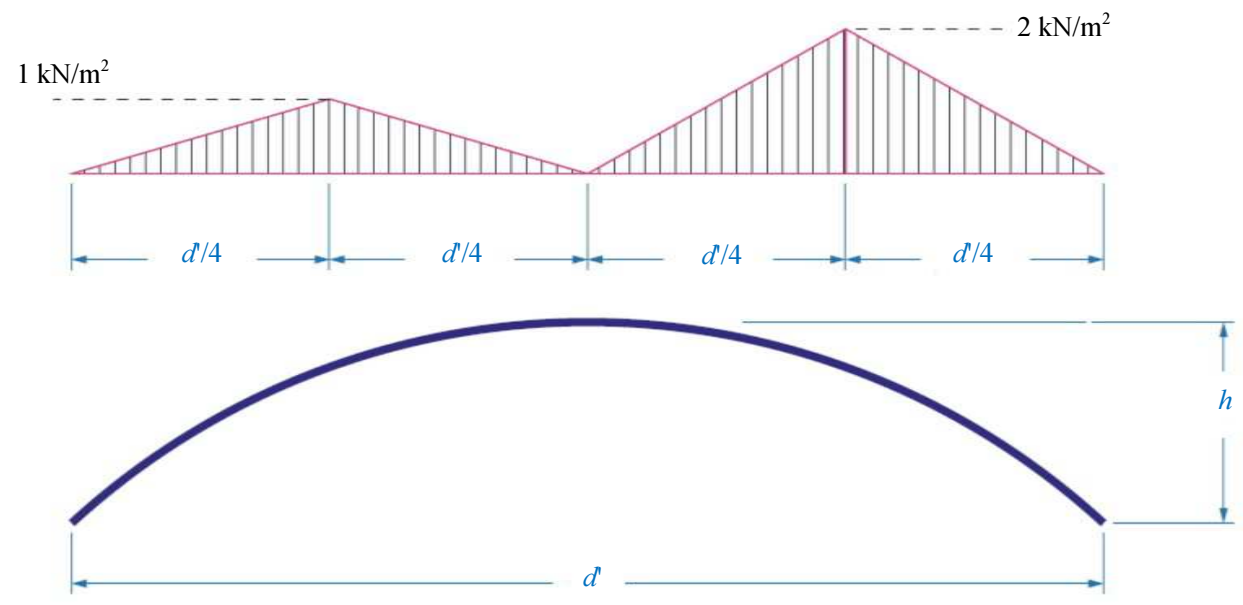

Fig. 13: Drifted snow load arrangement according to EuroCode 1 (EN. EN1991-1-3: 2004) 


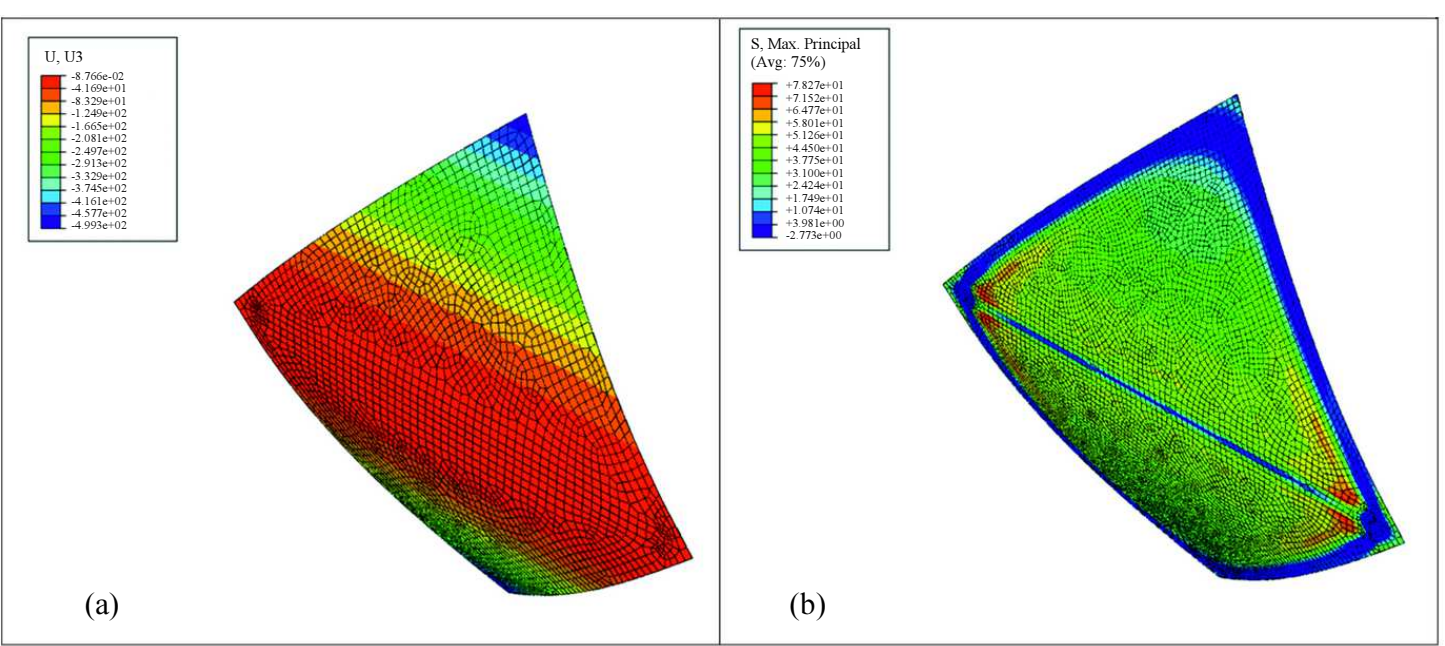

Fig. 14: "Maximum opening" configuration. Results of FE analysis, in terms of (a) out-of-plane displacement and (b) maximum principal stress in the thin glass panel

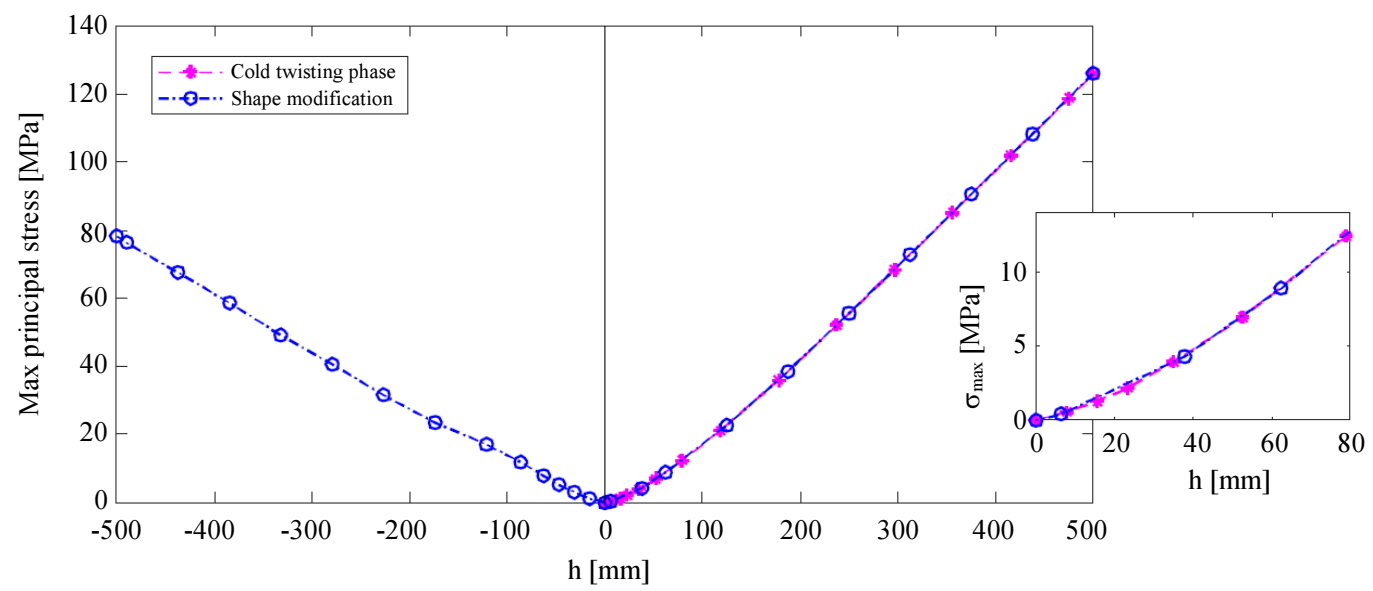

Fig. 15: Relation between prescribed out-of-plane displacement and maximum principal stress in glass, for cold twisting and shape modification

Graph in Fig. 15 show the numerically obtained relationship between prescribed out-of-plane displacement and maximum principal stress in glass, for both cold twisting and shape modification phases. The magnified detail highlights the nonlinearity of the relation, similar to that recorded in (Van Herwijnen et al., 2004) for cold bending of glass with standard thickness. The numerical findings confirm that the loading (cold bending) and unloading (i.e., shape modification from $h=500 \mathrm{~mm}$ to the flat configuration) path coincide. The asymmetry of the graph is due to the presence of the metallic frame.

\section{Reduced-Scale Model}

\section{The Elementary Cell and its Movimentation}

A reduced scale mock-up of the whole greenhouse, with scale factor 1:6.67, have been constructed, to study the kinetics of the roof and its obtainable transformation. The first stage of the design-byprototyping has been devoted to the study of both the shape modification of the single elements composing the greenhouse roof and of the required movimentation. The square cells, with edge length of $300 \mathrm{~mm}$ and constructed with square acetate foils 400 $\mu \mathrm{m}$ thick$^{5}$, have been curved in the reference configuration by prescribing a vertical displacement of the cell corners of $75 \mathrm{~mm}$ with respect to the undeformed (flat) configuration. The metallic elements are represented by blue stripes.

As discussed in the previous Sections, the movimentation system should be designed so to

${ }^{5}$ To respect the scale factor, the thickness should be 300 $\mu \mathrm{m}$, but, due to the unavailability on the market of acetate foils with this thickness, $400 \mu \mathrm{m}$ have been used. 
prescribe vertical (out-of-plane) displacement to the corners' points, while leaving the in-plane translational and the rotational degrees of freedom. In particular, when moved from the reference curved configuration to the atone, the corner point of the reduced-scale mockup displaces of $19 \mathrm{~mm}$ in horizontal (diagonal) direction. In the reduced-scale model, a dovetail-shaped joint is used to connect the plate with a wooden vertical rod. Figure $16 \mathrm{a}$ and $16 \mathrm{~b}$ show this connection, in the flat configuration and for a corners' displacement of $-h$ (directed upward, correspondent to the maximum opening of the roof), respectively.

In the reduced-scale mock-up, the movable corners may be fixed in different position, with vertical displacement of $h$ (correspondent to the reference configuration), $h / 2,0$ (flat configuration), $-h / 2$ and $-h$ (maximum opening). Figure 17 shows the configuration of a single cell for these values of corners' displacement, highlighting the possible shape modifications.

This design-by-prototyping study has confirmed, at least from a qualitative point of view, that the considered deformation modes do not entail uncontrolled changes of curvature and snapping phenomena. Furthermore, the construction of the reduced-scale model has highlighted the feasibility of the proposed concept and it has provided evidence that a key point in the greenhouse design is the study of the vertical constraint for the cell vertex.

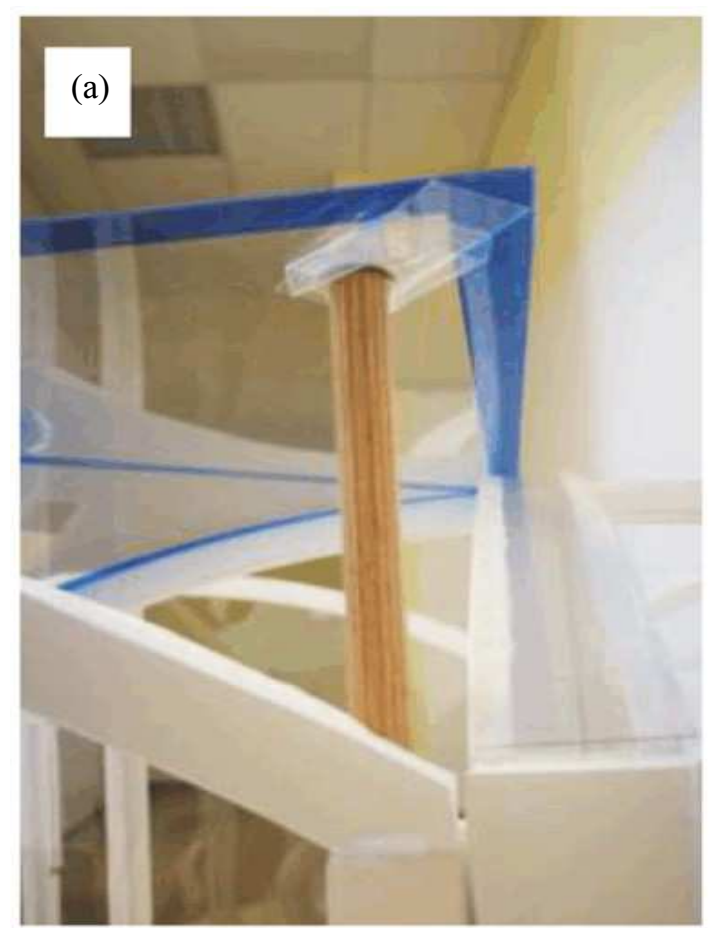

\section{The Greenhouse and its Different Configuration}

In a second phase, a reduced-scale mock-up of the whole greenhouse has been constructed. The substructure, shown in Fig. 18a, consists into perimetric walls, with the geometry represented in Fig. 9 and four curved ribs connecting the center of each edge with a central square column. This substructure has been realized with foam core cardboard, while panel composing the walls of the greenhouse have been made with $100 \mu \mathrm{m}$ thick acetate foils.

The shape modification of the roof is obtained by vertically moving the corners' points of each cell, by means of the wooden vertical rods shown in Fig. 16, that can be moved upward and downward inside hollow columns located in proximity of the midpoint of the greenhouse edges (Fig. 18b). The reference configuration, with vertical displacement of the cell corners of $h=75 \mathrm{~mm}$ with respect to their undeformed flat configuration, is shown in Fig. 19.

The reduced-scale mock-up is very useful for illustration and demonstration purposes, in particular to display the possible shape modification of the greenhouse roof. Figure 20 shows several possible configurations for the roof, correspondent to those presented in Fig. 8a-8e and highlights the huge range of obtainable shapes and opening systems.

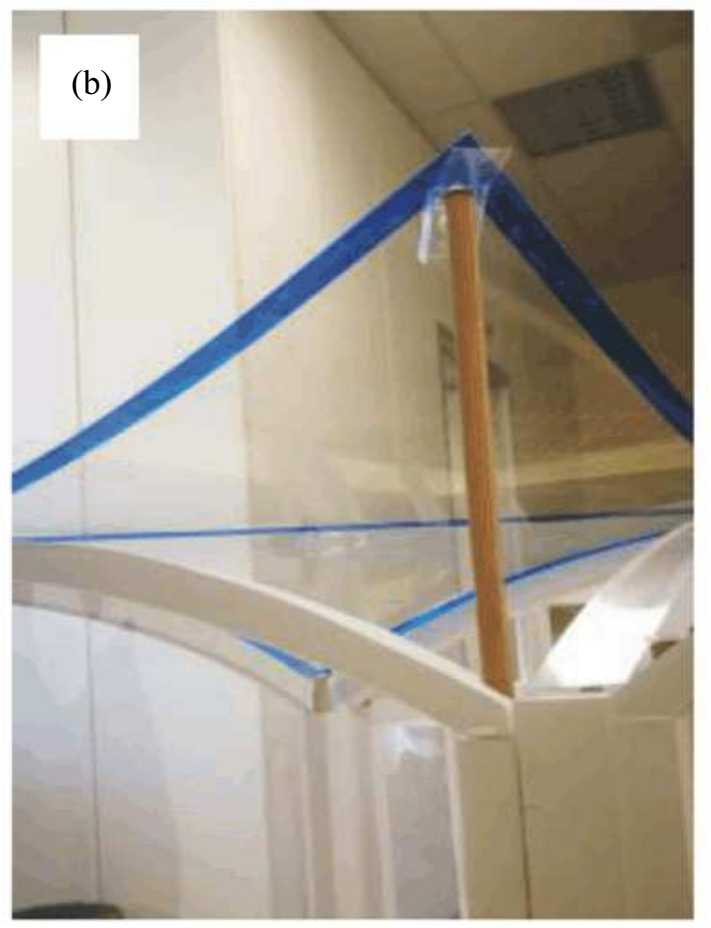

Fig. 16: Dovetail-shaped connection between plate and vertical rod (a) flat configuration and (b) corners' displacement of $-h$ 

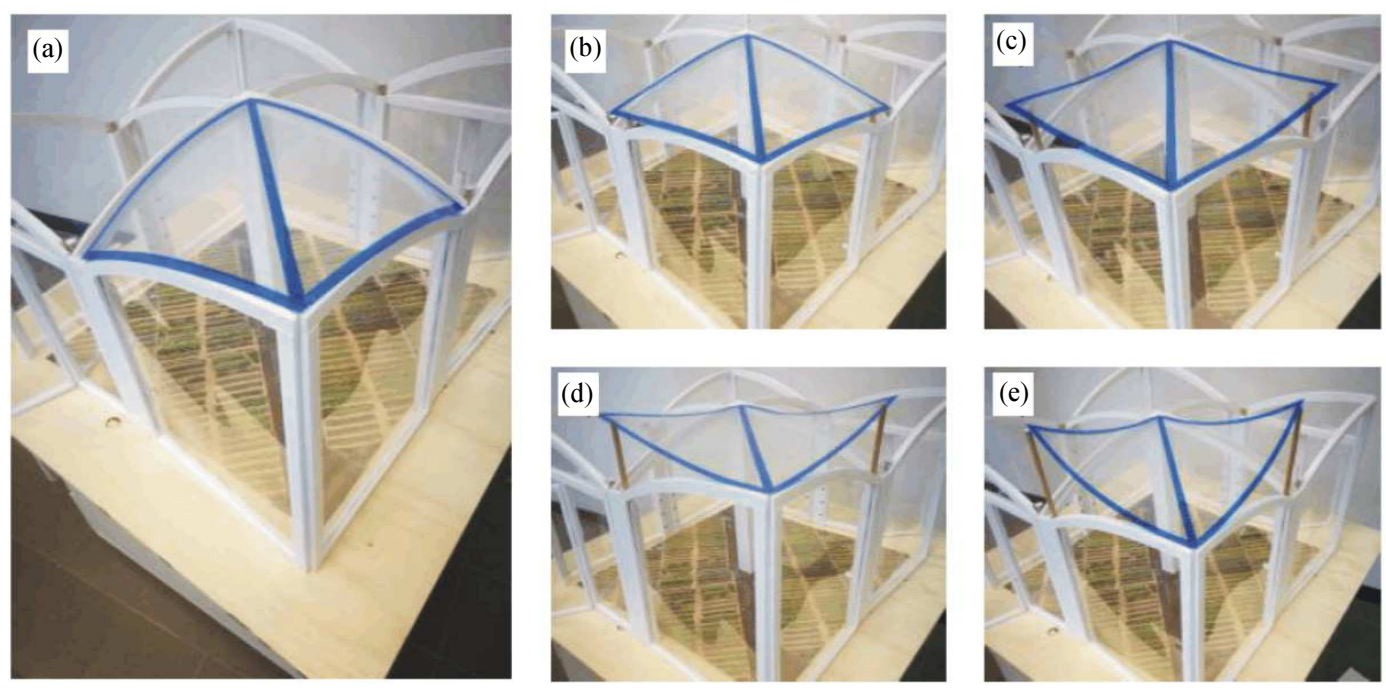

Fig. 17: (a) Reduced-scale model of the single cell in the reference configuration and its possible shape modifications, with corners' displacement of (b) $h / 2$, (c) 0 (flat configuration), (d) $-h / 2$ and (e) $-h$
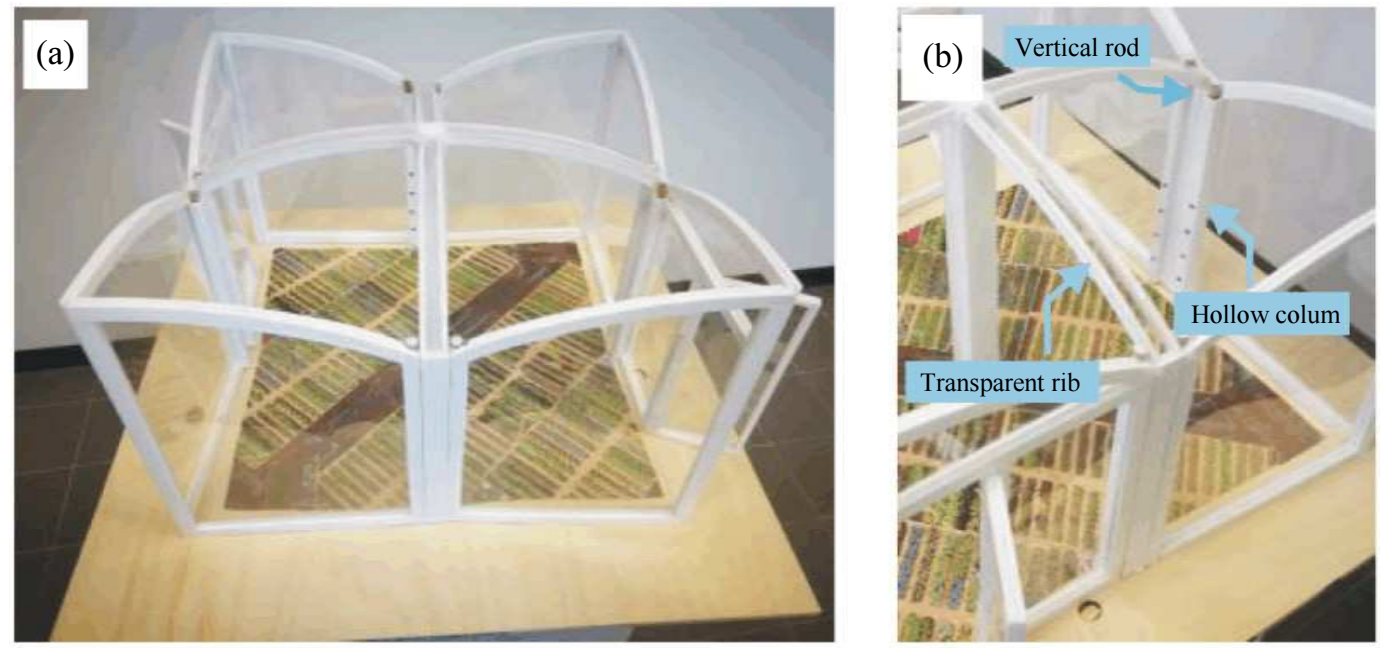

Fig. 18: (a) Greenhouse substructure and (b) particular of the transparent ribs, the hollow columns and the vertical rods
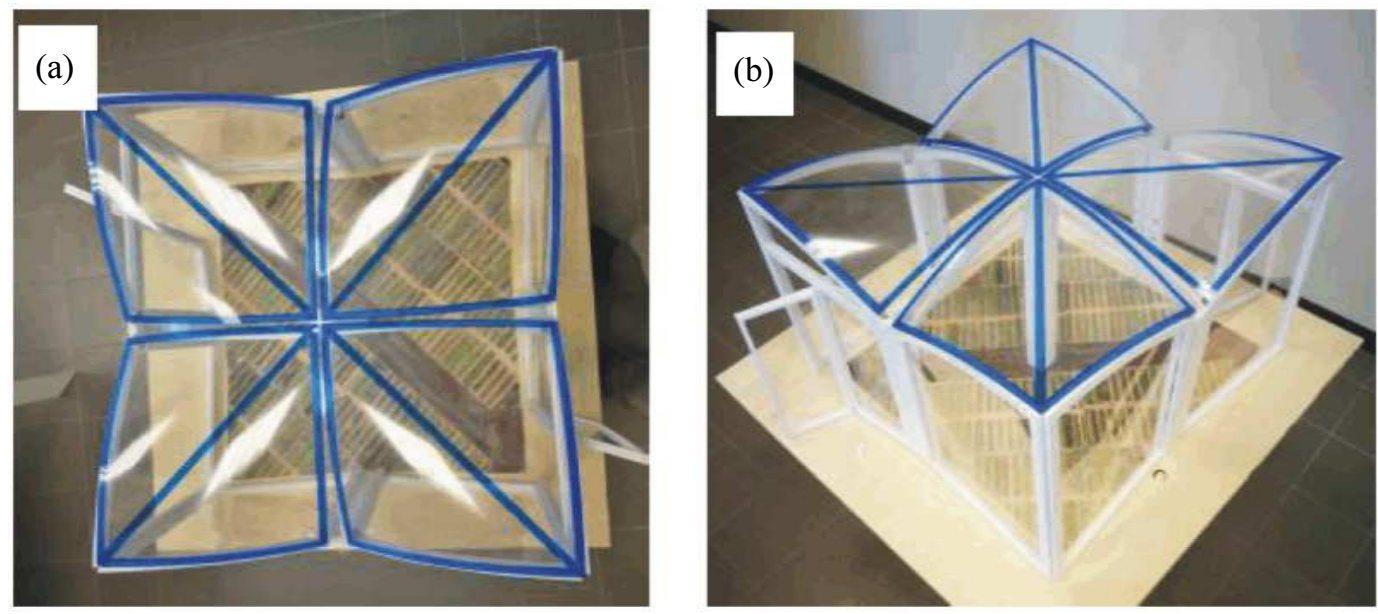

Fig. 19: Reference configuration of the greenhouse (a) top view and (b) perspective view 

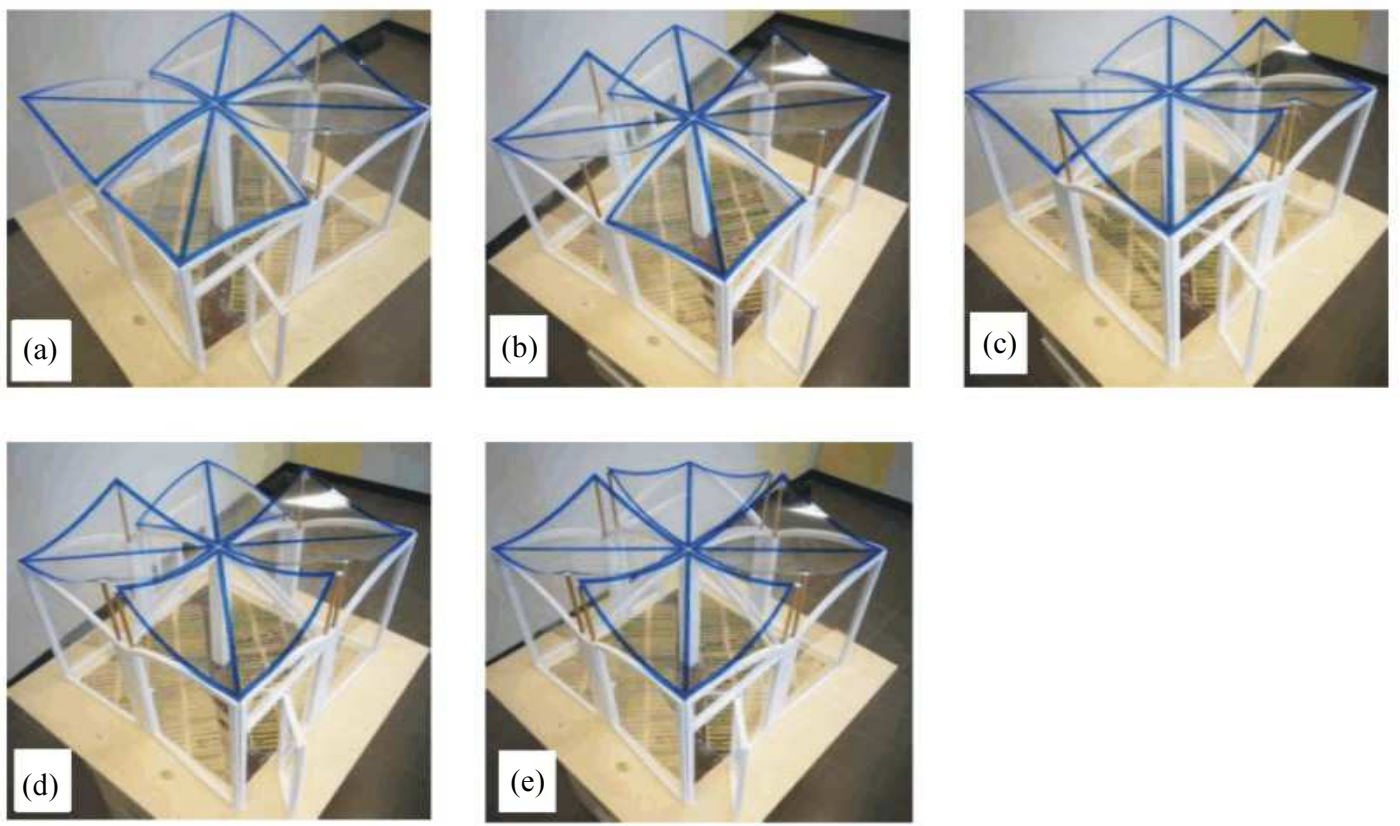

Fig. 20: Reduced-scale model. Different configurations for the greenhouse roof

\section{Discussion and Conclusion}

Due to the high flexibility of thin glass, new design options become feasible in comparison to regular thicknesses of glass. This paper presents a innovative application of thin glass in the build environment, in particular for the construction of deformable greenhouse for protected agriculture.

With respect to other recent studies, where thin glass is used for movable and adaptive systems where the transparent elements are moved and/or rotated to modify the skin geometry (Neugebauer, 2015), here the main feature of this material, that is undoubtedly its flexibility, is fully exploited. Indeed, the elementary cell composing the roof is a steel-thin glass square composite panel, cold-bent, along a diagonal, into a developable cylindrical surface. Starting from this configuration, the shape of the panel may be modified by keeping fixed the two corners' points belonging to the straight diagonal, while moving the other corners in the out-of-plane direction, so to change the concavity of the curved diagonal. On this basis, a movable and deformable roof is designed, constituted by four elementary cells, cylindrical in shape and cold-bent along a diagonal. The straight diagonals of the cells converge towards the center of the greenhouse, conferring the esthetic appearance of a flower with four "petals".

To optimize the design, different materials and geometries for the hybrid cell have been considered. In particular, a ferritic stainless steel frame with one diagonal rib, bonded to the glass panel with SikaTack ${ }^{\circledR}$ MOVE Transportation adhesive, is used, so to have a diagonal more compliant than the other. This confers to the composite cell a preferential direction to the bending deformation. The shape change may be obtained in a gradual way, by progressively moving the corners' of the plate, to obtain several intermediate positions.

The composite cell has been numerically designed to with stand the loads necessary to the cold bending and to the shape modification, as well as the self weight and the snow load, according to Eurocode 1. Particular attention have been paid to the possible arising of local instability phenomena, especially during the shape modification of the roof. In particular, FE analyses considering the effect of the snow load have highlighted that, due to the curvature of glass, the panel presents very high stiffness and strength and consequently stresses and deflection due to the this load are almost negligible if compared to those due to the cold twisting. In conclusion, this study shows that the use of thin glass deformable panels in a façade or roof can achieve interesting results regarding both visual effect, ventilation and structural response, confirming the findings of (Silveira, 2016). The design of the structure has been achieved also through a "design-byprototyping" strategy. The construction of a reducedscale mock-up of the entire greenhouse, of approximatively $60 \times 60 \mathrm{~cm}$ and made of acetate foils and foam core card board, has confirmed, even if from a qualitative point of view, the feasibility of the proposed concept and that the considered deformation modes do not entail abrupt change of curvature. Furthermore, it has consistently helped the study of the kinetics, highlighting in particular of the importance of the study of the vertical actuator for the cell vertex and of the obtainable 
transformation. This could also allow to evaluate the natural ventilation paths in the different configurations.

Further developments of the present work would be the design of the greenhouse structure, that should be able to with stand the roof weight and the accurate study of the movimentation of the column supporting the movable corners of the cells composing the greenhouse roof. Other several aspect, from energetic and environmental issues, to the evaluation of the relation between required transient agroecosystem parameters (in terms of temperature, humidity, light intensity, air exchange rate, etc.) and structural aspects, could be taken into consideration. Since these issues are related to topics as ventilation strategies and relations among transmissivity, solar radiation/reflection and orientation/inclination of greenhouse surfaces, multidisciplinary approach will be very useful to evaluate the correlation of these requirements with the size, geometry and shapes of the structure (i.e., orientation, lighting, ventilation, etc.) and, in particular, with the required modifications and transformations.

This will pave the way for a proper monitoring and retrofitted control of climate and agro/biological parameters of the greenhouse. By means of a control system, determining the movements of the vertical rods supporting the movable corners of the cell, the greenhouse should be turn into an adaptive structure, capable of changing shape and openings to meet the transient requirements.

\section{Acknowledgement}

The author acknowledges the financial support of the University of Parma (Italy) under project FIL 2016"Quota incentivante".

The author also acknowledge G. D'Ambrosio for the precious support in the preparation of the reduced-scale mock-up.

\section{Ethics}

The Author declare there is not conflict of interest and no ethical issue arose. This article is original and contains unpublished material.

\section{References}

ABAQUS, 2010. Analysis user manual, version 6.10. Simulia, ABAQUS.

Alotaibi, F., 2015. The role of kinetic envelopes to improve energy performance in buildings. J. Architectural Eng. Technol., 4: 149-149. DOI: $10.4172 / 2168-9717.1000149$

Beatini, V. and G. Royer-Carfagni, 2017. Large transformations with moderate strains of tensile membrane structures. Math. Mechan. Solids, 22: 1717-1737. DOI: $10.1177 / 1081286516643360$
Bedon, C., D. Honfi, M. Kozłowski, K.V. Machalická and F. Santos et al., 2018. Key structural aspects for adaptive facades - activity progress from the EUCOST Action TU1403 'structural' task group. Int. J. Structural Glass Adv. Mater. Res.

Belis, J., B. Inghelbrecht, R. Van Impe and D. Callewaert, 2007. Cold bending of laminated glass panels. Heron, 52: 123-146. heronjournal.nl/52-12/6.pdf

Bijster, J., C. Noteboom and M. Eekhout, 2016. Glass entrance van Gogh museum Amsterdam. Glass Struct. Eng., 1: 205-231. DOI: $10.1007 / \mathrm{s} 40940-016-0022-5$

Boaz, P., 2010. Tempering very thin glass-what radio waves mean for the glass industry. USGlass Magazine.

Datsiou, K., 2017. Design and Performance of Cold Bent Glass. PhD Thesis, University of Cambridge.

de Wit, J.M., 2009. Computational modeling of cold bent glass panels. MSc Thesis, Delft University of Technology, Delft (NL).

Eekhout, M. and S. Niderehe, 2009. The new, cold bent glass roof of the Victoria AND Albert Museum, London. Proceedings of the Glass Performance Days, (GPD' 09), Finland, pp: 408-412.

EN. EN1991-1-3: 2004. Eurocode 1-Actions on structures-Part 1-3: General actions-snow loads.

Fildhuth, T. and J. Knippers, 2014. Interior stress monitoring of laminated cold bent glass with Fibre Bragg sensors. Proceedings of the Challenging Glass 4 and COST Action TU0905 Final Conference, (FC' 14), Taylor and Francis Group, London, pp: 105-112.

Fildhuth, T., J. Knippers, F. Bindji-Odzili, N. Baldassini and S. Pennetier, 2014. Recovery behavior of laminated cold bent glass-numeric alanlysis and testing. Proceedings of the Challenging Glass 4 and Cost Action TU0905 Final Conference, (FC' 14), Lausanne, pp: 113-121.

Galuppi, L., P. Di Biase, B. Schaaf, C. Richter and B. Hoffmeister et al., 2018. Hybrid steel-glass cell: Cold-twisting and buckling phenomena. Proceedings of the Challenging Glass Conference, (CGC' 18), At Delft, pp: 217-228.

Galuppi, L., S. Massimiani and G. Royer-Carfagni, 2014. Buckling phenomena in double curved coldbent glass. Int. J. Non-Linear Mechan., 64: 70-84. DOI: 10.1016/j.ijnonlinmec.2014.03.015

Galuppi, L. and G. Royer-Carfagni, 2014. Rheology of cold-lamination-bending for curved glazing. Eng. Struct., 61: 140-152.

DOI: 10.1016/j.engstruct.2014.01.003

Galuppi, L. and G. Royer-Carfagni, 2015a. Coldlamination-bending of glass: Sinusoidal is better than circular. Comp. Part B: Eng., 79: 285-300. DOI: 10.1016/j.compositesb.2015.04.024 
Galuppi, L. and G. Royer-Carfagni, 2015b. On the occurrence of lumped forces at corners in classical plate theories: A physically based interpretation. J. Mechan. Mater. Struct., 10: 93-103.

DOI: $10.2140 /$ jomms.2015.10.93

Galuppi, L. and G. Royer-Carfagni, 2015c. Optimal cold bending of laminated glass. Int. J. Solids Struct., 67: 231-243. DOI: 10.1016/j.ijsolstr.2015.04.023

Ganatra, P., 2016. Bamboo and thin glass: Structural analysis of bending bamboo and thin glass. MSc Thesis, Delft University of Technology, Delft (NL). https://repository.tudelft.nl/islandora/object/uuid\%3 A5ad68271-1707-4c30-b989-5a19a3cb0

GhaffarianHoseini, A.H., N.D. Dahlan, U. Berardi, A. GhaffarianHoseini and N. Makaremi et al., 2013. Sustainable energy performances of green buildings: A review of current theories, implementations and challenges. Renewable Sustainable Energy Rev., 25: 1-17. DOI: 10.1016/j.rser.2013.01.010

Goel, N. and M.K. Gurve, 2018. Greenhouse monitoring system using internet of things and cloud-based technology. Proceedings of the $3 \mathrm{rd}$ International Conference on Internet of Things and Connected Technologies, Mar. 26-27, Malaviya National Institute of Technology, Jaipur. DOI: 10.2139/ssrn.3171506

Gupta, G.S. and V.M. Quan, 2018. Multi-sensor integrated system for wireless monitoring of greenhouse environment. Proceedings of the IEEE Sensors Applications Symposium, IEEE Xplore Press, Seoul, South Korea, pp: 1-6. DOI: $10.1109 /$ SAS.2018.8336723

Gy, R., 2008. Ion exchange for glass strengthening. Mater. Sci. Eng., 149: 159-165.

DOI: 10.1016/j.mseb.2007.11.029

Hoffmeister, B., P. Di Biase, C. Richter and M. Feldmann, 2017. Innovative steel-glass components for high-performance buildings kins: Testing of fullscale prototypes. Glass Struct. Eng., 2: 57-78. DOI: $10.1007 / \mathrm{s} 40940-016-0034-1$

Hou, Y., J. Cheng, J. Kang, H. Li and J. Cui et al., 2017. Simulation of the glass melt flowing during the slit down draw process. IOP Conf. Series: Mater. Sci. Eng., 274: 012080-012080.

DOI: $10.1088 / 1757-899 \mathrm{X} / 274 / 1 / 012080$

Lin, H.J. and W.K. Chang, 2007. Design of a sheet forming apparatus for overflow fusion process by numerical simulation. J. Non-Crystalline Solids, 353: $2817-2825$.

DOI: $10.1016 /$ j.jnoncrysol.2007.06.022

Lin, H.J. F.Y. Hsu and W.K. Chang, 2008. Effect of isopipe temperature on the glass sheet forming for overflow fusion process by numerical simulation. Adv. Mater. Res., 39: 512-517.

DOI: 10.4028/www.scientific.net/AMR.39-40.517
Linn, C., 2014. Kinetic Architecture: Design for Active Envelopes. 1st Edn., Images Publishing, ISBN-10: 1864704950, pp: 224.

Loonen, R.C.G.M., F. Favoino, J.L.M. Hensen and M. Overend, 2017. Review of current status, requirements and opportunities for building performance simulation of adaptive facades. J. Build. Performance Simulat., 10: 205-223.

DOI: $10.1080 / 19401493.2016 .1152303$

Mansfield, E.H., 1955. The inextensional theory for thin at plates. Q J. Mechan. Applied Math., 8: 338-352. DOI: 10.1093/qjmam/8.3.338

Mansfield, E.H., 1964. The bending and stretching of plates. Cambridge University Press.

Maschmeyer, R.O., J.C. Thomas and K.L. Wasson, 2018. High strength glass having improved mechanical characteristics. USPatent 9,975, 801.

Morales-Beltran, M. and P. Teuffel, 2013. Towards smart building structures: Adaptive structures in earth quake and wind loading control response-a review. Intell. Build. Int., 5: 83-100. DOI: $10.1080 / 17508975.2013 .778193$

Neugebauer, J., 2015. A movable canopy. Proceedings of the International Conference on Building Envelope Design and Technology, (EDT' 15), Advanced Building Skins, Graz, pp: 324-324.

Neugebauer, J., M. Wallner-Novak, T. Lehner, C. Wrulich and M. Baumgartner, 2018. Movable thin glass elements in façades. Challeng. Glass Conf. Proce., 6: 195-202. DOI: 10.7480/cgc.6.2133

Omrany, H., A. GhaffarianHoseini, A.H. GhaffarianHoseini, K. Raahemifar and J. Tookey, 2016. Application of passive wall systems for improving the energy efficiency in buildings: A comprehensive review. Renewable Sustainable Energy Rev., 62: 1252-1269. DOI: 10.1016/j.rser.2016.04.010

MacFarlane, T., I. Iori, D. Maccari, L Galuppi and L. Biolzi et al., 2018. Innovative steel glass composite structures for high-performance building skins $(\mathrm{S}+\mathrm{G})$. Final Report, Technical report, Research for Coal and Steel (RFCS), Project RFSR-CT-2012-00026.

Silveira, R.R., 2016. Flexible transparency: A study on thin glass adaptive façade panels. MSc Thesis, Delft University of Technology, Delft (NL).

Silveira, R.R., C. Louter and T. Klein, 2018. Flexible transparency-a study on adaptive thin glass façade panels. Challeng. Glass Conf. Proc., 6: 135-148.

Staaks, D., 2003. Koud torderen van glaspanelen in blobs (Cold Bent Glass Sheets in blobs), in German. MSc Thesis, University of Technology Eindhoven, Eindhoven (NL).

Timoshenko, S.P. and S. Woinowsky-Krieger, 1959. Theory of Plates and Shells. 1st Edn., McGraw-Hill, ISBN-10: 0070647798, pp: 580. 
Topçu, O., 2017. Kinetic thin glass façade. MSc Thesis, Delft University of Technology, Delft (NL).

Van Herwijnen, F., D. Staaks and M. Eekhout, 2004. Cold bent glass sheet sin façade structures. Struct. Eng. Int., 14: 98-101.

Varshneya, A.K., 2010. Chemical strengthening of glass: Lessons learned and yet to be learned. Int. J. Applied Glass Sci., 1: 131-142.
Zeljic, A.S., 2010. Shanghai tower façade design process. Proceedings of the International Conference on Building Envelope Systems and Technologies, (EST’ 10), Vancouver, Canada. 